\title{
Numerical Analysis in Ultrasonic Elliptical Vibration Cutting (UEVC) Combined With Electrical Discharge Cutting (EDC) For Ti6Al4V
}

Rendi Kurniawan

Yeungnam University

Moran Xu

Yeungnam University

Chang Ping Li

Hunan University of Science and Technology

Gun Chul Park

Yeungnam University

Ye In Kwak

Yeungnam University

Jielin Chen

Yeungnam University

Tae Jo Ko ( $\nabla$ tjko@yu.ac.kr)

Yeungnam University

\section{Research Article}

Keywords: Finite-element-analysis, vibration-assisted-cutting, hybrid cutting, numerical analysis, ellipticalvibration-assisted-cutting, ABAQUS

Posted Date: November 2nd, 2021

DOl: https://doi.org/10.21203/rs.3.rs-998144/v1

License: (c) (1) This work is licensed under a Creative Commons Attribution 4.0 International License. Read Full License 
Numerical Analysis in Ultrasonic Elliptical Vibration Assisted Cutting (UEVC) Combined with Electrical Discharge Cutting (EDC) for Ti6Al4V

\section{Numerical Analysis in Ultrasonic Elliptical Vibration Cutting (UEVC) Combined with Electrical Discharge Cutting (EDC) for Ti6Al4V}

\section{Authors Information:}

Rendi Kurniawan ${ }^{1, *}$, Moran $\mathrm{Xu}^{1}$, Chang Ping $\mathrm{Li}^{2}$, Gun Chul Park ${ }^{1}$, Ye In Kwak ${ }^{1}$, Jielin Chen $^{1}$, Tae Jo Ko ${ }^{1, *}$

\section{Affiliation:}

1 Precision Machining Laboratory room 214, Department of Mechanical Engineering, Yeungnam University, South Korea.

2 Faculty of Mechanical and Electromechanical Engineering, Hunan University of Science and Technology, Taoyuan Road, Xiangtan, Hunan, China

Corresponding authors*:

Prof. Dr. Tae Jo Ko, email : tjko@yu.ac.kr

*Corresponding authors: tjko@yu.ac.kr 
Numerical Analysis in Ultrasonic Elliptical Vibration Assisted Cutting (UEVC) Combined with Electrical Discharge Cutting (EDC) for Ti6Al4V

\section{ABSTRACT}

This paper reports the numerical analysis results of ultrasonic elliptical vibration cutting (UEVC) combined with the electrical discharge cutting (EDC), called UEVC+EDC. UEVC delivers decreasing cutting forces, repressing side-burrs, and lowering tool wear. $E D C$ is a cutting technique using a pulsed spark to remove material using thermal energy. Difficult-to-cut materials, such as Ti-6Al-4V, can be cut effectively by combining these two techniques. A numerical study was performed using ABAQUS finite element analysis (FEA) software by investigating the von Mises stress, cutting forces, and temperature. Numerical analysis was carried out by modifying the ultrasonic vibration frequency, distance of the discharge pulse, discharge voltage, and discharge pulse radius. UEVC+EDC was compared numerically and experimentally with regular cutting (NC) and UEVC in terms of cutting force and tool temperature. The results showed that the UEVC+EDC method could improve the cutting condition by reducing the cutting force and von Mises stress and increasing the tool temperature.

Keywords: Finite-element-analysis; vibration-assisted-cutting; hybrid cutting; numerical analysis; elliptical-vibration-assisted-cutting; ABAQUS

\section{INTRODUCTION}

Ultrasonic vibration-assisted cutting (UVAC) [1] can improve the cutting performance in difficult-to-cut materials (e.g., titanium alloys [2], Inconel 718 [3], brittle materials [4], and ceramic materials [5]), such as lowering the stress in the primary deformation zone [6], repressing side-burrs [7], suppressing flank wear [8], and improving roughness [9] with relatively low cutting speeds owing to its intermittent cutting characteristics. UVAC is classified as non-traditional cutting in which the tool is commonly vibrated with an actuator/transducer (e.g., magnetic-coil/piezo-electric actuator [10], or ultrasonic perpendicular Langevin horn [11]) to produce high mechanical vibration energy at high frequencies to enhance material removal.

The UVAC method, according to the number of tool directions, has been classified as one-, two- or even three-dimensional directions [10]. In addition, comprehensive review papers on UVAC have been published with several topics, such as 1D- and 2Dvibration-assisted machining (VAM) [12], designing apparatus for VAM [13][14], vibration-assisted milling [15], feasibility study for aircraft materials [16], related to advanced materials [10], and micro/nano textured surfaces [17].

In the case of one-dimensional ultrasonic vibration-assisted cutting (1D-UVAC), this cutting method has been explored extensively, including experimental [18], FEA simulation [19], and theoretical models [20]. In 1D-UVAC, the tool modulates commonly in parallel, perpendicular, or even in the feed direction of the workpiece surface [10]. Recent investigations of 1D-UVAC since 2017 focused on surface texturing [21], microtextured surface [22], the influence of the tool material and geometry [23], development in the micro-milling device [24], and cutting force prediction using FEA [25]. 1D-UVAC 
Numerical Analysis in Ultrasonic Elliptical Vibration Assisted Cutting (UEVC) Combined with Electrical Discharge Cutting (EDC) for Ti6Al4V

accomplished revolutionary analyses, particularly in the cutting mechanism [19]. Therefore, the 1D-UVAC was not assessed in this study.

2D-UVAC involves two directions of tool motion along with the cutting speed and the thrust direction. In 2D-UVAC, the tool motion is elliptical/oval or even circular in stationary vibration. 2D-UVAC has also been explored extensively, and advances have been made in terms of experimental [1, 4], FEA simulations [6, 26, 27], and mathematical models [28, 29]. The recent publications since 2017 in 2D-UVAC involved surface roughness analysis [9], bone-cutting [30], atomistic investigation [31], nano-cutting [32], surface sculpturing [33], brittle-to-ductile transition [34], diffraction texturing effect [35], and tribology [36]. Accordingly, 2D-UVAC has become the best candidate to replace conventional techniques because of the simple implementation and apparatus. Therefore, this study examined this technique further by combining it with a thermal effect.

In the case of 3D-UVAC, the tool vibrates sequentially along in three directions to form a 3D elliptical locus in Cartesian coordinate space. Shamoto et al. [37] reported the first investigation of 3D-elliptical vibration cutting in 2008. Some studies on 3D-UVAC have been published since 2017, such as device development [38][39], surface topography [40], carbon-fiber-reinforced plastic (CFRP) [41], surface integrity [42], wettability [43] and surface texturing [44]. Despite the research on 3D-UVAC in specific topics, the breakthrough of the cutting mechanism of 3D-UVAC could still be explored. In this study, however, 2D-UVAC combined with the electrical discharge cutting (EDC) technique is the focus; 3D-UVAC will be a future research topic.

Thermally Assisted Cutting (TAC) has been investigated extensively, and some reviews regarding this method are available [45-48]. TAC uses an external heat source, such as a laser [49] and plasma [50] device. The external heat source is used to localized preheat the workpiece surface, thereby decreasing the hardness and yield strength of the workpiece surface during machining. This decreases the cutting forces after localized preheating, minimizing tool wear and surface roughness [51]. On the other hand, the EDC technique can become an alternative external heat source. Jung et al. [52] used EDC in the assisted cutting of Ti6Al4V during micro-dimpling to decrease the cutting force. Few studies have examined the use of EDC in the TAC technique. Therefore, the EDC is proposed as the external heat source for this hybrid technique.

The EDC technique is categorized as a non-traditional cutting technique for high precision products and complex-shape cutting. In this study, EDC was combined with the 2D-UVAC method. The EDC technique is fundamentally electrical discharge machining (EDM). The EDC technique only operates with conducting materials. In the EDC technique, surface materials are removed by melting and vaporization from the discharged plasma spark, regardless of its hardness, where the discharged spark temperature is higher than the melting temperature of the workpiece. The materials properties in EDC, e.g., the thermal conductivity, melting temperature, and electrical conductivity, become important in the EDC technique [53]. In the EDC technique, dielectric fluids [54], such as deionized water and kerosene, are commonly used to occupy the dielectric medium between the tool and workpiece. In addition, the dry condition could also be employed [55]. 
Numerical Analysis in Ultrasonic Elliptical Vibration Assisted Cutting (UEVC) Combined with Electrical Discharge Cutting (EDC) for Ti6Al4V

The EDC technique has been investigated comprehensively, and research advances have been made [56]. Moreover, reviews regarding the EDC technique alone have been available broadly, e.g., surface modification [57], hybrid machining process [58], dielectric fluids [59], difficult-to-machine materials [60], metal matrix composites [61], and modelling/optimization [62]. Therefore, the EDC technique is not new in industry. On the other hand, the authors combined this EDC technique with the 2D-UVAC to determine the thermal effect on the material during vibration cutting using the FEA method.

This study used the dry-EDC technique. The dry-EDC is a variation of the EDC, which means the EDC technique is performed without dielectric fluids. Recent research since 2019 on dry-EDC has been performed. Macedo et al. [63] examined the anode power deposition in dry-EDC, focusing on the theoretical modeling of discharged plasma physics became their interest. The workpiece or the anode material absorbed approximately $80 \%-90 \%$ of the discharged plasma power, whereas the discharged plasma power loss by convection and radiation was considered. Jung et al. [52] studied the mechanism of micro-EDC drilling under dry conditions focusing on modeling the cutting forces. A decrease in cutting forces was observed due to the thermal softening effect. Dhakar et al. [64] conducted an experimental study comparing wet-EDC and neardry EDC. Toxicological emissions produced higher quantities in the wet-EDC. Therefore, the dry-EDC can be categorized as environment-friendly.

The EDC technique has been combined in recent times with several other cutting methods, such as ultrasonic motion [65], electro-chemical spark machining (ECM) [66], milling [67], and grinding [68]. Zhang et al. [69] examined ultrasonic-assisted micro-EDC, where a nitrogen plasma jet was also investigated. The ultrasonic vibration helps remove the debris easily from the discharged area. Thus, abnormal discharged sparks could be decreased and the cutting efficiency enhanced. Their results confirmed that the material removal rate (MMR) could be improved by adding an ultrasonic vibration effect. Li et al. [70] evaluated a hybrid method (EDC and Milling) for titanium alloy cutting. They proposed a special cutting tool to work sequentially between conventional milling and EDC. A decrease in cutting forces, reduced tool wear, removal of side-burrs, and improvement of surface roughness were achieved [70]. On the other hand, the hybrid technique regarding the combination between 2D-UVAC and EDC has not been accomplished and was the motivation for this research.

The FEA method is an extremely useful tool to analyze cutting parameters that cannot be measured during experiments, such as plastic strain, plastic strain rate, stress, and temperature in the primary shear deformation zone. Recent observations based on FEA and numerical in vibration-assisted cutting have been obtained. Zhenzhi et al. [71] studied the UVAC on bone material experimentally and numerically. The numerical FEA could predict the cutting forces and cutting temperature. In addition, the cutting forces in UVAC were lower than those in normal cutting. Chen et al. [19] examined vibrationassisted micro-milling numerically and experimentally. They concluded that the vibration frequency greatly affects the machining mechanism. More cracks were observed in the primary deformation zone in vibration-assisted milling than in conventional milling based on the numerical study. 
Numerical Analysis in Ultrasonic Elliptical Vibration Assisted Cutting (UEVC) Combined with Electrical Discharge Cutting (EDC) for Ti6Al4V

Gracia et al. [25] estimated the specific cutting energy for multi-directional ultrasonic vibration-assisted cutting using numerical analysis. A low average cutting force could be achieved when the tool was not permanently in contact with the deformed chip. In addition, the specific cutting energy was low when the vibration frequency was high. Xiang et al.[72] examined the FEA in ultrasonic-assisted milling in a specific case of SiCpAl composites. In the case of a single particle of SiCp-Al composites, a high frequency could decrease particle breakage and low crack growth. The ultrasonic amplitude also affected the particle breakage, even though a proper amplitude must be selected to minimize particle breakage [72]. Lotfi et al. [73] assessed ultrasonic-assisted drilling experimentally and numerically. Their findings were similar to other studies in which ultrasonic vibrations affect the cutting mechanism, such as decreasing the cutting forces, reducing the cutting temperature, and lowering the built-up-edge. According to the literature above, ultrasonic vibration has a significant effect on metal cutting.

Overall, the hybrid cutting technique (2D-UVAC combined with the EDC (UEVC+EDC)) has not been implemented. This study proposed a novel FEA model that may be implemented in industry. The hybrid technique was proposed and carried out by numerical analysis in a two-dimensional manner. The cutting parameters, such as vibration frequency, discharge voltage, discharged radius, and discharge distance, were adjusted. The surface node temperature, cutting tool temperature, cutting forces, stress, and strain rate were analyzed accordingly. These findings are useful in metal cutting, especially in non-traditional cutting mechanisms.

\section{NUMERICAL METHODOLOGY}

Numerical analysis was carried out using commercial ABAQUS ${ }^{\mathrm{TM}} 2019$ software. Dynamic explicit coupled temperature analysis was implemented. In this study, twodimensional (2D) analysis with deformable characteristics for both the workpiece and tool were considered. The titanium alloy (Ti6AI4V) and tungsten carbide were considered as a material for the workpiece and the tool, respectively. Table 1 lists their properties, where the workpiece Young's Modulus was considered to decrease with increasing temperature. The detailed descriptions regarding the boundary condition, meshing, contact interaction, $\mathrm{J}-\mathrm{C}$ constitutive model, and Gaussian pulsed model are described in the next sub-chapter.

The following assumptions were made with the numerical model of UEVC+EDC:

1. The EDC model was considered only for a single park and pulsation.

2. The Gaussian heat flux distribution was used as described in Eq. 6.

3. The thermal properties of the workpiece material were varied according to the temperature, as shown in Table 1.

4. The material properties were homogeneous and isotropic.

5. The dynamic explicit couple temperature analysis was used in this study.

6. The initial temperature was distributed equally at $25^{\circ} \mathrm{C}$, and transient type analysis was utilized.

7. The NC (Normal Cutting) and UEVC were also performed for comparison with UEVC+EDC. The vibrations of the tool and Gaussian heat flux were not given for the NC method. The Gaussian heat flux was not given only for the UEVC method. 
Numerical Analysis in Ultrasonic Elliptical Vibration Assisted Cutting (UEVC) Combined with Electrical Discharge Cutting (EDC) for Ti6Al4V

\subsection{FEA setup (boundary condition, meshing, and contact interaction)}

Fig. 1 describes the FEA boundary condition of the hybrid cutting technique used in this study. The workpiece had a length of $400 \mu \mathrm{m}$ a height of $200 \mu \mathrm{m}$. The workpiece was moved relative to the time in the left direction with a constant cutting velocity, $\mathrm{V}_{\mathrm{c}} . \mathrm{A}$ zero reference $[x=0, y=0]$ was set at the top left of the workpiece, as shown in Fig. 1 . The cutting tool had the following geometry: a rake angle of $7^{\circ}$, flank angle of $7^{\circ}$, and the tool edge radius $R_{\text {edge }}$ of $10 \mu \mathrm{m}$. The tool was considered to vibrate in a fixed position, which is the tool position $\left(x_{t}, y_{t}\right)$, according to Eq. (1). The workpiece moved according to the relative position $\left(x_{w}, y_{w}\right)$ in Eq. (2).

$$
\begin{array}{r}
x_{t}(t)=a_{x} \sin \left(2 \pi f_{v} t\right)+a_{x} \\
y_{t}(t)=a_{y} \sin \left(2 \pi f_{v} t-\theta\right)+a_{y} \\
x_{w}(t)=V_{c} \cdot t \\
y_{w}(t)=0
\end{array}
$$

where $a_{x}$ and $a_{y}$ are the amplitude in the $\mathrm{x}$ - and $\mathrm{y}$-axis directions, as shown in Fig. 1 , which was set to $10 \mu \mathrm{m}$ for both directions. $f_{v}$ is the ultrasonic vibration frequency, which was set to be equal between 20 and $60 \mathrm{kHz}$. $t$ is the numerical time. $\theta$ is the phase shift difference between two sinusoidal motions, which were set to $90^{\circ} . V_{c}$ is the constant cutting velocity along the $x$-axis direction, which has a negative direction and was set to $2 \mathrm{~m} / \mathrm{s}$. This value was chosen considering that machining was carried out under a medium cutting speed in ordinary cutting, such as milling

This numerical study used the VDISP subroutine algorithm for 'user defined' definition in ABAQUS while applying the boundary conditions for tool vibration. Fig. 2 presents the VDISP code to conduct the numerical simulation. All scales in this numerical study were in SI units [m, $\mathrm{kg}, \mathrm{Pa}$, and J]. The FORTRAN compiler should be installed on the computer because it is an essential add-in to run the VDISP subroutine function. In this case, the authors installed Microsoft ${ }^{@}$ Visual Studio Community 2019, Intel ${ }^{@}$ oneAPI Base Toolkit, and Intel ${ }^{@}$ oneAPI HPC Toolkit. The FORTRAN compiler must be linked with ABAQUS software inside the ABAQUS batch command 'abq2019.bat' by adding the call function (@call “...”) opened using the Notepad++ program (see Fig. 2).

The meshing of the workpiece was quad-type (CPE4RT) for the Explicit library, and the coupled temperature-displacement was used. The geometric order was linear. The distortion control was set as a default, and the hourglass control was set as enhanced. The second-order accuracy was used, and plane strain type analysis was used. The element size was set to approximately $5 \mu \mathrm{m}$ for the workpiece. For the cutting tool, the tri-type of mesh was used with the couple temperature-displacement. The element size was formed as dense as the cutting edge of approximately $2 \mu \mathrm{m}$, and the outer side edge that does not engage with the workpiece was set to approximately $10 \mu \mathrm{m}$. Moreover, the contact interaction was set for the explicit surface-to-surface contact. The surface of the 
Numerical Analysis in Ultrasonic Elliptical Vibration Assisted Cutting (UEVC) Combined with Electrical Discharge Cutting (EDC) for Ti6Al4V

tool was coupled together with the reference point. Table 1 lists the material properties of Ti6Al4V in the tool and workpiece.

\subsection{Johnson-Cook Constitutive Model}

The plastic deformation of the material is generally justified according to three factors (strain hardening term, thermal softening, and strain rate hardening [74]). In this study, the plastic deformation of Ti6Al4V was justified using the Johnson-Cook constitutive model, as shown in Eq. 3 [74], which was set in the ABAQUS material properties.

$$
\sigma=\left(A+B \varepsilon^{n}\right)\left(1+C \ln \left(\frac{\dot{\bar{\varepsilon}}}{\dot{\overline{\varepsilon_{o}}}}\right)\right)\left(1-\left(\frac{T-T_{o}}{T_{m}-T_{o}}\right)^{m}\right)
$$

where $\sigma$ is the plastic stress flow; $\varepsilon$ is the equivalent plastic strain; $\dot{\bar{\varepsilon}}$ is the plastic strain rate; $\dot{\overline{\varepsilon_{O}}}$ is the reference or absolute strain rate $\left(1 \mathrm{~s}^{-1}\right) . A$ is the yield strength of the workpiece; $B$ is the hardening modulus; $C$ is the strain rate coefficient. $T$ is the cutting temperature on the primary deformation zone; $T_{o}=25^{\circ} \mathrm{C} ; T_{m}$ is the melting temperature of the workpiece. Table 2 lists the material constant for the Johnson-Cook model with $n$ and $m$ coefficients set to 0.34 and 0.8 , respectively.

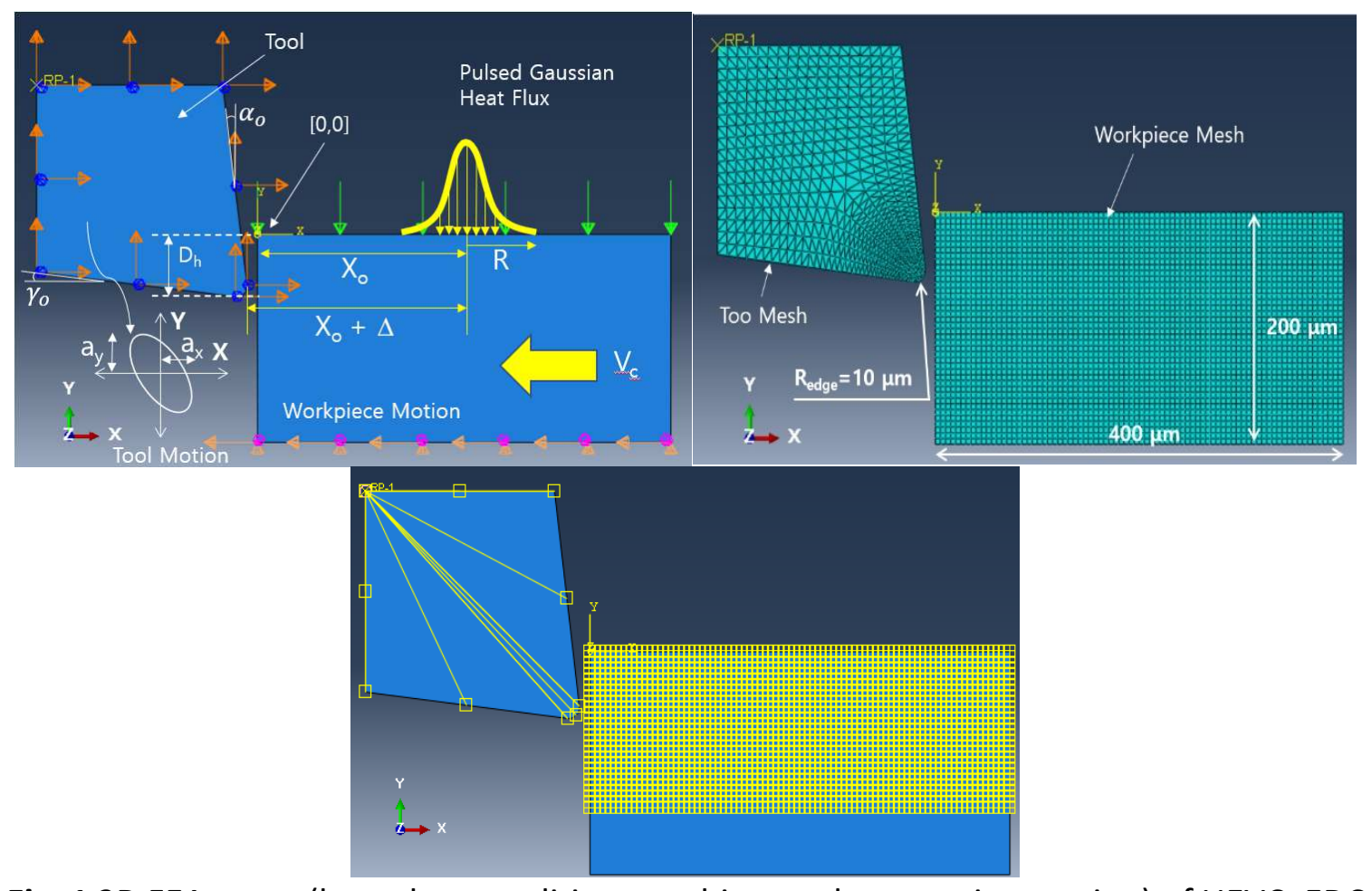

Fig. 1 2D FEA setup (boundary condition, meshing, and contact interaction) of UEVC+EDC implemented in this study. 
Numerical Analysis in Ultrasonic Elliptical Vibration Assisted Cutting (UEVC) Combined with Electrical Discharge Cutting (EDC) for Ti6Al4V

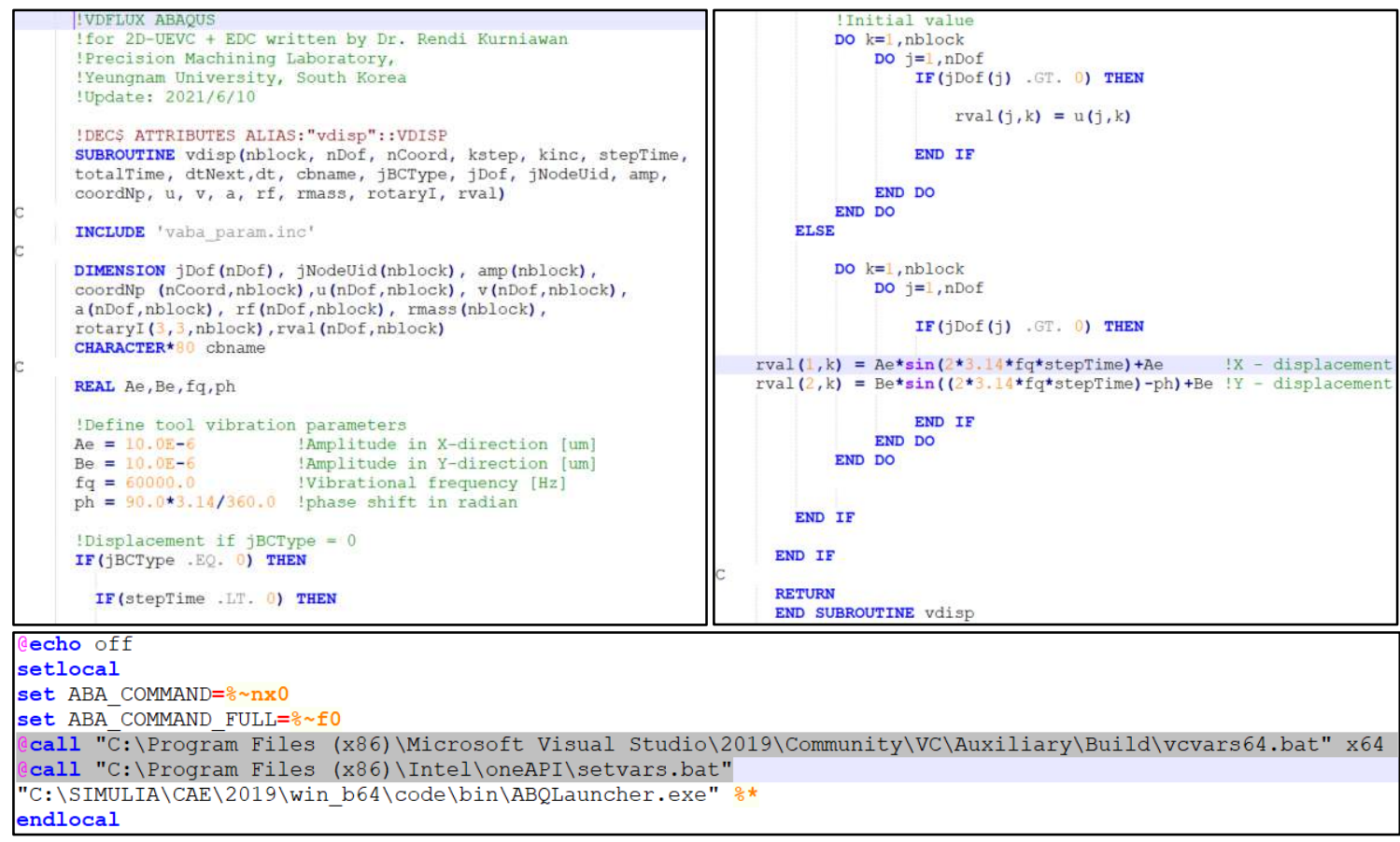

Fig. 2 VDISP subroutine for tool vibration and FORTRAN compiler linking the call function

Table 1 Material properties of Ti6Al4V and the tool properties [75]

\begin{tabular}{|l|l|l|}
\hline Properties & Ti6Al4V (Workpiece) & Tool (Tungsten Carbide) \\
\hline Conductivity $\left[\mathrm{W} / \mathrm{m}^{\circ} \mathrm{C}\right]$ & $6.8\left[T=20^{\circ} \mathrm{C}\right]$ & 50 \\
\hline & $7.4\left[T=100^{\circ} \mathrm{C}\right]$ & \\
\hline & $9.8\left[T=300^{\circ} \mathrm{C}\right]$ & \\
\hline & $11.8\left[T=500^{\circ} \mathrm{C}\right]$ & \\
\hline & & 400 \\
\hline Specific heat $\left[\mathrm{J} / \mathrm{kg}^{\circ} \mathrm{C}\right]$ & $611\left[T=20^{\circ} \mathrm{C}\right]$ & \\
\hline & $624\left[T=100^{\circ} \mathrm{C}\right]$ & \\
\hline & $674\left[T=300^{\circ} \mathrm{C}\right]$ & \\
\hline & $703\left[T=500^{\circ} \mathrm{C}\right]$ & \\
\hline Inelastic heat fraction & & \\
\hline & 0.9 & \\
\hline Elastic modulus $[\mathrm{Pa}]$ & $109 \times 10^{9}\left[T=20^{\circ} \mathrm{C}\right]$ & $534 \times 10^{9}$ \\
\hline & $91 \times 10^{9}\left[T=100^{\circ} \mathrm{C}\right]$ & \\
\hline & $75 \times 10^{9}\left[T=300^{\circ} \mathrm{C}\right]$ & \\
\hline & & \\
\hline Density $\left[\mathrm{kg} / \mathrm{m}^{3}\right]$ & 4,430 & 11,900 \\
\hline & & \\
\hline Poisson's ratio & 0.34 & \\
\hline & & \\
\hline
\end{tabular}


Numerical Analysis in Ultrasonic Elliptical Vibration Assisted Cutting (UEVC) Combined with Electrical Discharge Cutting (EDC) for Ti6Al4V

Table 2 Johnson-Cook constants of Ti6Al4V

\begin{tabular}{|l|l|}
\hline$A[P a]$ & $862 \times 10^{6}$ \\
\hline$B[P a]$ & $331 \times 10^{6}$ \\
\hline$C$ & 0.035 \\
\hline$n$ & 0.34 \\
\hline$m$ & 0.8 \\
\hline$\dot{\varepsilon}_{o}$ & 1 \\
\hline$T_{m}\left[{ }^{\circ} \mathrm{C}\right]$ & 1605 \\
\hline$T_{r}\left[{ }^{\circ} \mathrm{C}\right]$ & 25 \\
\hline
\end{tabular}

Table 3 Johnson-Cook damage parameters [75]

\begin{tabular}{|c|c|c|c|c|c|c|c|}
\hline $\boldsymbol{D}_{1}$ & $\boldsymbol{D}_{\mathbf{2}}$ & $\boldsymbol{D}_{\mathbf{3}}$ & $\boldsymbol{D}_{\mathbf{4}}$ & $\boldsymbol{D}_{\mathbf{5}}$ & $\boldsymbol{T}_{\boldsymbol{m}}$ & $\boldsymbol{T}_{\boldsymbol{r}}$ & $\dot{\boldsymbol{\varepsilon}}^{*}$ \\
\hline-0.09 & 0.25 & 0.5 & 0.014 & 3.87 & 1605 & 25 & 1 \\
\hline
\end{tabular}

Table 4 Numerical cutting and experimental cutting conditions

\begin{tabular}{|c|c|c|c|c|c|c|c|c|c|}
\hline \multicolumn{2}{|c|}{$\begin{array}{c}\text { NC } \\
\text { [Numerical] }\end{array}$} & \multicolumn{2}{|c|}{$\begin{array}{c}\text { UEVC } \\
\text { [Numerical] }\end{array}$} & \multicolumn{2}{|c|}{$\begin{array}{c}\text { UEVC } \\
\text { [Experimental] }\end{array}$} & \multicolumn{2}{|c|}{$\begin{array}{l}\text { UEVC+EDC } \\
\text { [Numerical] }\end{array}$} & \multicolumn{2}{|c|}{$\begin{array}{c}\text { UEVC+EDC } \\
\text { [Experimental] }\end{array}$} \\
\hline$V_{c}$ & $2 \mathrm{~m} / \mathrm{s}$ & $V_{c}$ & $2 \mathrm{~m} / \mathrm{s}$ & $\mathrm{V}_{\mathrm{c}}$ & $\begin{array}{c}0.169- \\
0.056 \\
\mathrm{~m} / \mathrm{s}\end{array}$ & $\mathrm{V}_{\mathrm{c}}$ & $2 \mathrm{~m} / \mathrm{s}$ & $\mathrm{V}_{\mathrm{c}}$ & $\begin{array}{c}0.169- \\
0.056 \\
\mathrm{~m} / \mathrm{s}\end{array}$ \\
\hline$D_{h}$ & $\begin{array}{l}100 \\
\mu \mathrm{m}\end{array}$ & $D_{h}$ & $\begin{array}{l}100 \\
\mu \mathrm{m}\end{array}$ & $D_{h}$ & $100 \mu \mathrm{m}$ & $D_{h}$ & $100 \mu \mathrm{m}$ & $D_{h}$ & $100 \mu \mathrm{m}$ \\
\hline feed & - & feed & - & feed & $\begin{array}{c}100 \\
\mu \mathrm{m} / \mathrm{rev}\end{array}$ & feed & - & feed & $\begin{array}{c}100 \\
\mu \mathrm{m} / \mathrm{rev}\end{array}$ \\
\hline$f_{v}$ & - & $\frac{f_{v}}{}$ & $\begin{array}{c}20-60 \\
\mathrm{kHz}\end{array}$ & $f_{v}$ & $\begin{array}{l}16.9 \\
\mathrm{kHz}\end{array}$ & $f_{v}$ & $\begin{array}{c}20-60 \\
\mathrm{kHz}\end{array}$ & $f_{v}$ & $16.9 \mathrm{kHz}$ \\
\hline$\theta$ & - & $\theta$ & $90^{\circ}$ & $\theta$ & $90^{\circ}$ & $\theta$ & $90^{\circ}$ & $\theta$ & $90^{\circ}$ \\
\hline S.R & - & S.R & $\begin{array}{c}0.628- \\
1.884 \\
\end{array}$ & S.R & $\begin{array}{c}0.628- \\
1.884 \\
\end{array}$ & S.R & $\begin{array}{c}0.628- \\
1.884 \\
\end{array}$ & S.R & $\begin{array}{c}0.628- \\
1.884 \\
\end{array}$ \\
\hline$a_{x}, a_{y}$ & - & $a_{x}, a_{y}$ & $10 \mu \mathrm{m}$ & $a_{x}, a_{y}$ & $1 \mu \mathrm{m}$ & $a_{x}, a_{y}$ & $10 \mu \mathrm{m}$ & $a_{x}, a_{y}$ & $1 \mu \mathrm{m}$ \\
\hline$x_{0}$ & - & $x_{0}$ & - & $x_{0}$ & & $x_{0}$ & $\begin{array}{c}50- \\
200 \mu \mathrm{m}\end{array}$ & $x_{0}$ & $5 \mathrm{~mm}$ \\
\hline$V_{d}$ & - & $V_{d}$ & - & $V_{d}$ & & $V_{d}$ & $\begin{array}{c}50- \\
250 \mathrm{~V}\end{array}$ & $V_{d}$ & $220 \mathrm{~V}$ \\
\hline $\mathrm{R}$ & - & $\mathrm{R}$ & - & $\mathrm{R}$ & & $\mathrm{R}$ & $\begin{array}{c}40-80 \\
\mu \mathrm{m}\end{array}$ & $\mathrm{R}$ & $40 \mu \mathrm{m}$ \\
\hline$l_{d}$ & - & $I_{d}$ & - & $I_{d}$ & & $I_{d}$ & $1 \mathrm{~A}$ & $I_{d}$ & $1 \mathrm{~A}$ \\
\hline$f_{p}$ & - & $f_{p}$ & - & $f_{p}$ & & $f_{p}$ & $\begin{array}{l}100 \\
\mathrm{kHz}\end{array}$ & $f_{p}$ & $100 \mathrm{kHz}$ \\
\hline$C_{p}$ & - & $C_{p}$ & - & $C_{p}$ & - & $C_{p}$ & - & $C_{p}$ & $1.5 \mu \mathrm{F}$ \\
\hline
\end{tabular}


Numerical Analysis in Ultrasonic Elliptical Vibration Assisted Cutting (UEVC) Combined with Electrical Discharge Cutting (EDC) for Ti6Al4V

\subsection{Johnson-Cook Damage Model}

The Johnson-Cook damage model can model a deformed chip during the numerical analysis of metal cutting. The element will generally be eroded or separated when the damage initiation parameter $D_{f}$ exceeds one [76]. The common $D_{f}$ value can be described using Eq. 4 [75], which is the summation ratio between the accumulation of changing of the equivalent strain in each numerical increment and the initial equivalent plastic strain at the start of a fracture $\varepsilon^{f}$, as expressed in Eq. 5 , where $D_{1}-D_{5}$ are the Johnson-Cook damage parameters for Ti6AI4V, as listed in Table. 3. In this study, however, the Johnson-Cook damage model for the ductile fracture criterion based on fracture energy was adopted. The fracture energy was set to $10,000 \mathrm{~J} / \mathrm{m}^{2}$ for damage evolution, where the multiplicative degradation was used. According to Zhang et al. [76], the formulation for the damage initiation parameter based on the damage energy can be described using Eq. 6, where $G_{f}$ is the Hillerborg's fracture energy; $u^{p}$ is the equivalent plastic displacement; $\sigma$ is the equivalent plastic stress. In this case, the deformation of the chip will not show a serrated surface.

$$
\begin{array}{r}
D_{f}=\sum \frac{\Delta \varepsilon}{\varepsilon^{f}} \\
\varepsilon^{f}=\left(D_{1}+D_{2} \exp \left(D_{3} \sigma^{*}\right)\right)\left(1+D_{4} \ln \left(\frac{\dot{\bar{\varepsilon}}}{\dot{\overline{\varepsilon_{o}}}}\right)\right)\left(1+D_{5}\left(\frac{T-T_{r}}{T_{m}-T_{r}}\right)\right) \\
D_{f}=1-\exp \left(-\int_{0}^{u^{p}} \frac{\sigma}{G_{f}} d u^{p}\right)
\end{array}
$$

\subsection{Pulsed Gaussian Heat Flux}

The plasma spark of the EDC process was assumed to be a pulsed Gaussian heat flux, as shown in the schematic diagram in Fig. 1. On the other hand, the plasma spark can be modeled as a uniform heat flux based on previous studies, such as micro-drilling with discharge cutting [52] or EDC [77]. In addition, the uniform heat flux can explain the thermal physics, but the Gaussian heat flux $[78,79]$ is preferable because it is more realistic in physics and for accuracy in numerical analysis. Eq. 7 expresses the pulsed Gaussian heat flux, where the center of pulsed Gaussian heat flux is located from the zero reference of the workpiece with a distance $X_{o}$ (see Fig. 1). The distance of the cutting tool tip nose from the zero reference of the workpiece, $\Delta=10 \mu \mathrm{m}$. The position of Gaussian heat flux is set in fixed as well as the cutting tool since the workpiece moves along $\mathrm{x}$-axis.

$$
Q(X)=f_{p} \frac{C_{f} \cdot V_{d} \cdot I_{d}}{\pi \cdot R^{2}} e^{-\left(\frac{k\left(X-X_{O}\right)\left(X-X_{O}\right)}{R^{2}}\right)}
$$


Numerical Analysis in Ultrasonic Elliptical Vibration Assisted Cutting (UEVC) Combined with Electrical Discharge Cutting (EDC) for Ti6Al4V

In Eq. 7, $Q$ is the heat flux distribution as a function of the $\mathrm{x}$-axis $(\mathrm{X})$ variable. $X_{O}$ was $50 \mu \mathrm{m}$ to $200 \mu \mathrm{m}$ (see the numerical model assumption point 7). $R$ is the radius of the pulsed Gaussian heat flux. The Gaussian shape coefficient $k$ equals $2 . V_{d}$ and $I_{d}$ are the discharge voltage and current, respectively. $C_{f}$ is the heat fraction number that determines how many percentages of heat energy penetrate the workpiece. $C_{f}$ was set to $18 \%(0.18)$ according to Liu and Gao's paper [79]. $f_{p}$ is the pulse frequency during the discharged simulation. The pulse frequency determines the number of cycles of the plasma spark formed across the discharged gap [57]. In this study, the pulse frequency was set constant at $100 \mathrm{kHz}$.

For numerical analysis, the heat flux was set on the workpiece surface, as shown in Fig. 1, and the DFLUX subroutine was written in notepad++ and saved as a FORTRAN function (".for"). Fig. 3 shows the DFLUX subroutine used in this study.

The UEVC+EDC method was simulated by varying the distance pulse $(50-200 \mu \mathrm{m})$, discharge voltage (50-250 V), pulsed radius $(40-80 \mu \mathrm{m})$, and ultrasonic frequency (20-60 $\mathrm{kHz}$ ). A cutting speed of $2 \mathrm{~m} / \mathrm{s}$, cutting depth of $100 \mu \mathrm{m}$ and discharged current of $1 \mathrm{~A}$ were maintained as constants. Table 4 lists the numerical cutting condition.
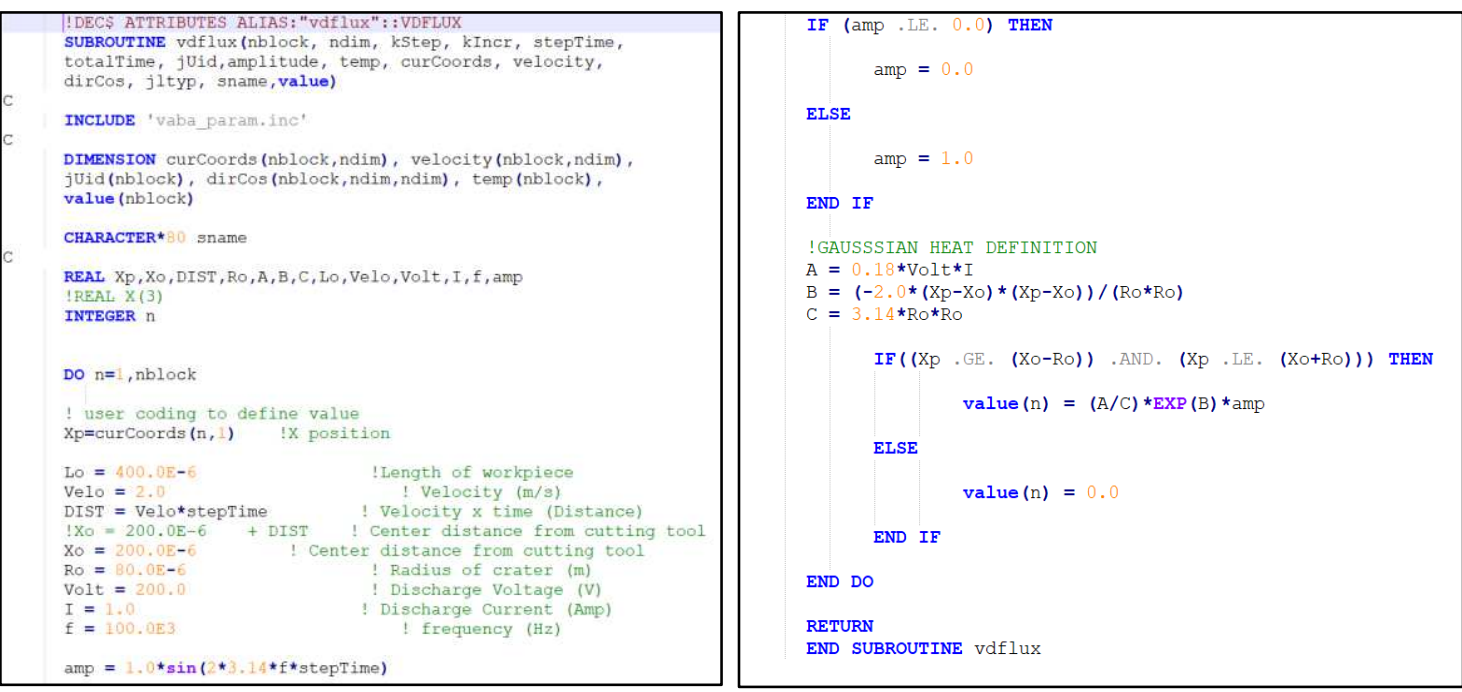

Fig. 3 VDFLUX subroutine for the Gaussian heat flux of the plasma spark

\section{EXPERIMENTAL SETUP}

The experimental UEVC and UEVC+EDC were conducted in the CNC lathe turning to validate numerical results, as shown in Fig. 4. Although the numerical models were conducted in a 2D platform, the numerical models still can be validated, particularly using a 3D platform, such as turning. Table 4 lists the detailed experimental setup for numerical and experimental trials. Experiments are difficult to perform precisely using similar numerical parameters because, in the numerical trials, the vibration frequencies were set at a high range of values: $20,30,40,50$, and $60 \mathrm{kHz}$. It was fundamentally considered for 
Numerical Analysis in Ultrasonic Elliptical Vibration Assisted Cutting (UEVC) Combined with Electrical Discharge Cutting (EDC) for Ti6Al4V

high-performance machining and in high cutting speeds, such as ultrasonic vibrationassisted milling.

Meanwhile, in the current setup, the ultrasonic tool holder was only working in a fixed natural frequency of approximately $16.9 \mathrm{kHz}$. Therefore, the S.R (Speed Ratio) was set to be similar between the numerical and experimental trials. S.R is the speed ratio between the cutting velocity and maximum vibration speed $\left(V_{c} / 2 \pi f_{v} a_{x}\right)$. S.R in the numerical trials is equal to $0.628,0.942,1.256,1.570$, and 1.884 with $f_{v}$ between 20 and $60 \mathrm{kHz}$, amplitude of $10 \mu \mathrm{m}$, and cutting velocity of $2 \mathrm{~m} / \mathrm{s}$. Thus, the rotational speeds of the workpiece in experimental trials were set to $120,80,60,48$, and $40 \mathrm{rpm}$ with a fixed vibration frequency of $16.9 \mathrm{kHz}$ and a vibrational amplitude of $1 \mu \mathrm{m}$ to maintain an equal S.R with the numerical study (see Table. 4). In addition, the phase shift vibration for the experiment was set to be similar at $90^{\circ}\left(120^{\circ}-30^{\circ}=90^{\circ}\right)$. An elliptical vibration was generated using an ultrasonic hybrid precision generator of three channels where channels 2 and 3 were activated, and channel 1 was off (see Fig. 4). The bending-bending vibration mode was activated using activated channels 2 and 3 only. The detailed design of the ultrasonic tool holder is reported elsewhere [44].

The cutting depth $D_{h}$ was set equal to $100 \mu \mathrm{m}$, which is similar to the numerical trials. On the other hand, the numerical trials did not have a feed rate of $100 \mu \mathrm{m} / \mathrm{rev}$. Thus, the numerical cutting forces must be multiplied by $0.01 \mathrm{~mm}^{2}\left(0.10 \times 0.10 \mathrm{~mm}^{2}\right)$. The mini dynamometer KISTLER type of $9256 \mathrm{C}$ was used to measure the cutting force signal. The mini dynamometer can measure the signal maximum at a frequency of approximately $5 \mathrm{kHz}$; thus, a signal with a frequency $>5 \mathrm{kHz}$ is probably eliminated. The DAQ (Data Acquisition) device of $\mathrm{NI}$ (National Instruments) PCI-E 6034E installed on the PC (Personal Computer) was used.

The NI PCI-E 6034E has a data speed of approximately 200 k Sample/s with an analog input of 16 channels. The sampling frequency of $40 \mathrm{kHz}$ and data sampling of $20 \mathrm{k}$ was set in LabVIEW 2011. No low pass filter was used to capture the force signal and thermocouple signal. The tool temperature was measured using thermocouple type $\mathrm{K}$ and recorded with the same DAQ NI PCI-E 6034E. The thermocouple was placed under the cutting tool, as shown in Fig. 4. The conventional tungsten carbide tool with a triangular shape was used. A FLIR camera type T540 IR camera with the setting of the emissivity of titanium material $(\approx 0.75)$ was used to record cutting temperature, especially around the chip deformation zone.

An adjustable copper electrode was used to perform the EDC technique, as shown in Fig. 4. The adjustable copper electrode had a circular shape similar to the workpiece shape. A manual one-axis micro-stage MMT-M1-338-C1 was used to adjust the discharged gap. The distance between the tool and Gaussian pulse in the numerical study was set to a maximum of approximately $200 \mu \mathrm{m}$. On the other hand, the distance between tool and copper electrode was set to $5 \mathrm{~mm}$ in the experimental setup because it is difficult to set it very close to the cutting tool, and it will disturb the chip flow. Accordingly, the distance was set to approximately $5 \mathrm{~mm}$ to allow space for escaping the deformed chip. The EDC was performed under dry conditions without a dielectric. The RC power generator was used to perform EDC, as shown in Fig. 4. The discharged voltage was set to a maximum of approximately $220 \mathrm{~V}$ with a discharge capacitance $C_{p}$ of $1.5 \mu \mathrm{F}$. The 
Numerical Analysis in Ultrasonic Elliptical Vibration Assisted Cutting (UEVC) Combined with Electrical Discharge Cutting (EDC) for Ti6Al4V

discharged radius was measured using a 3D optical surface profiler. The most common diameter of the micro-crater was approximately $40-110 \mu \mathrm{m}$, as shown in Fig. 5. Generally, the plasma spark dimensions are related to the micro-crater diameter. Therefore, the plasma spark radius in the numerical trials was approximately 40,60 , and $80 \mu \mathrm{m}$.

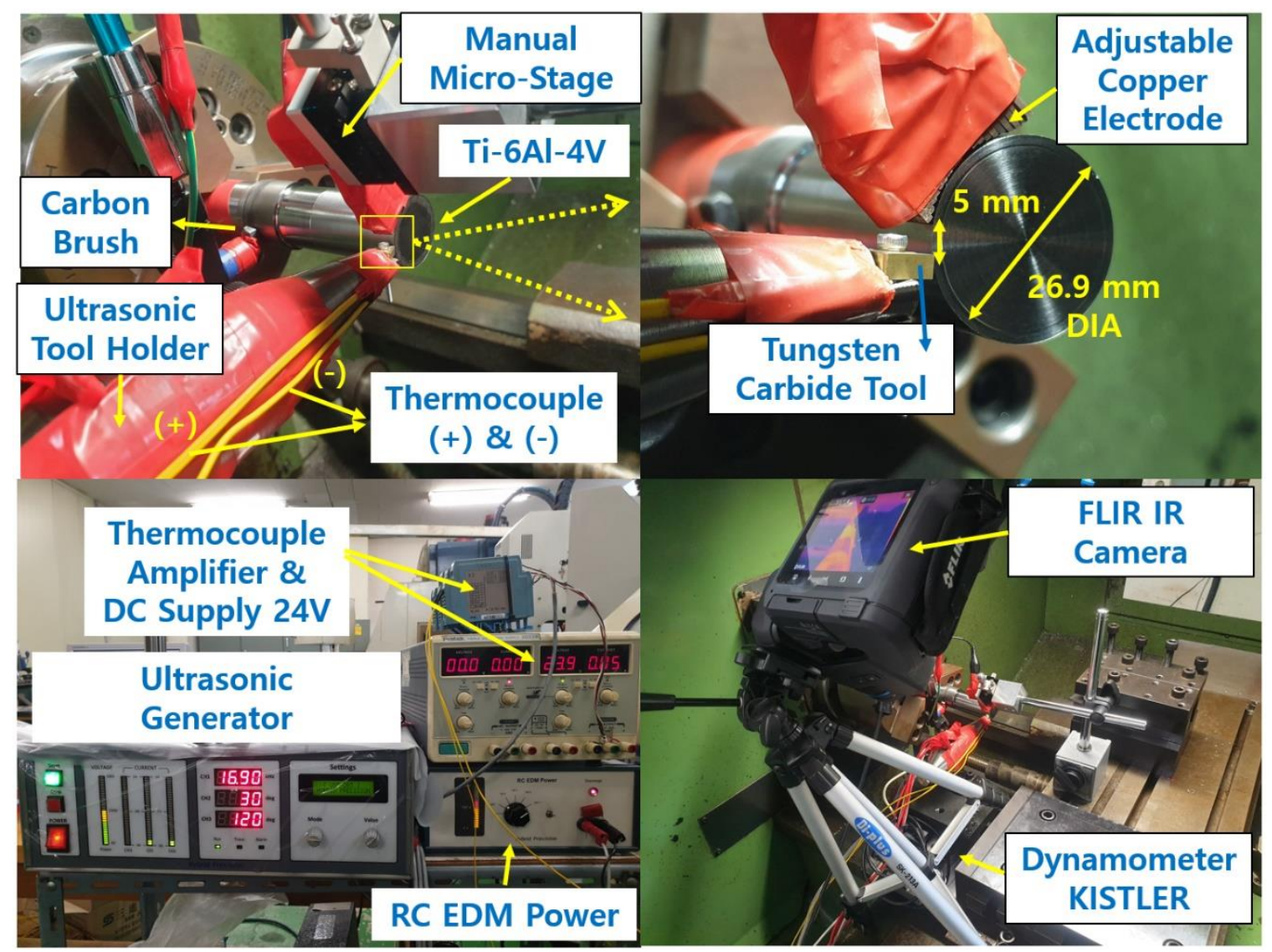

Fig. 4 Experimental setup for the numerical validation of UEVC+EDC

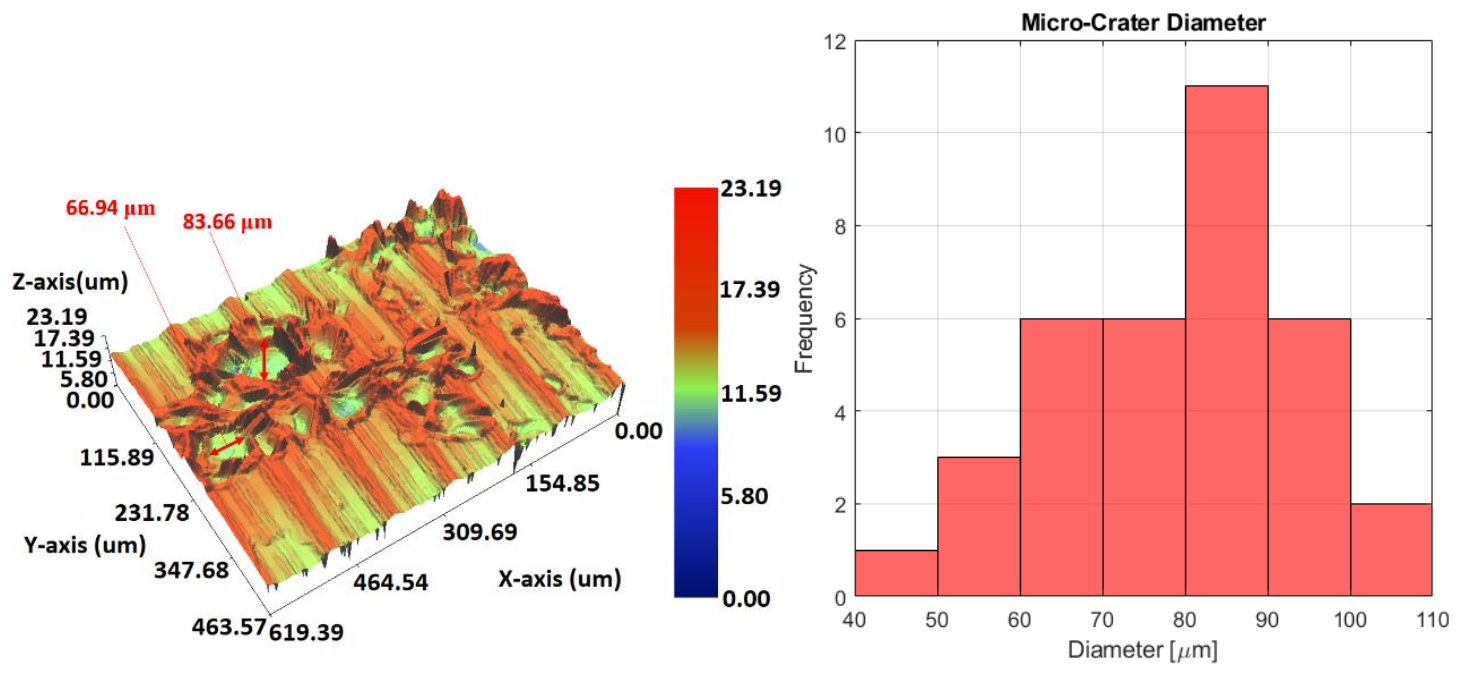


Numerical Analysis in Ultrasonic Elliptical Vibration Assisted Cutting (UEVC) Combined with Electrical Discharge Cutting (EDC) for Ti6Al4V

Fig. 5 3D-profile of a typical micro-crater produced using EDC method $V_{d}: 220 V C_{p}: 1.5$ $\mu \mathrm{F}$ and histogram of the micro-crater diameter

\section{RESULTS and DISCUSSIONS}

\subsection{Numerical Stress and Temperature Contour Comparison}

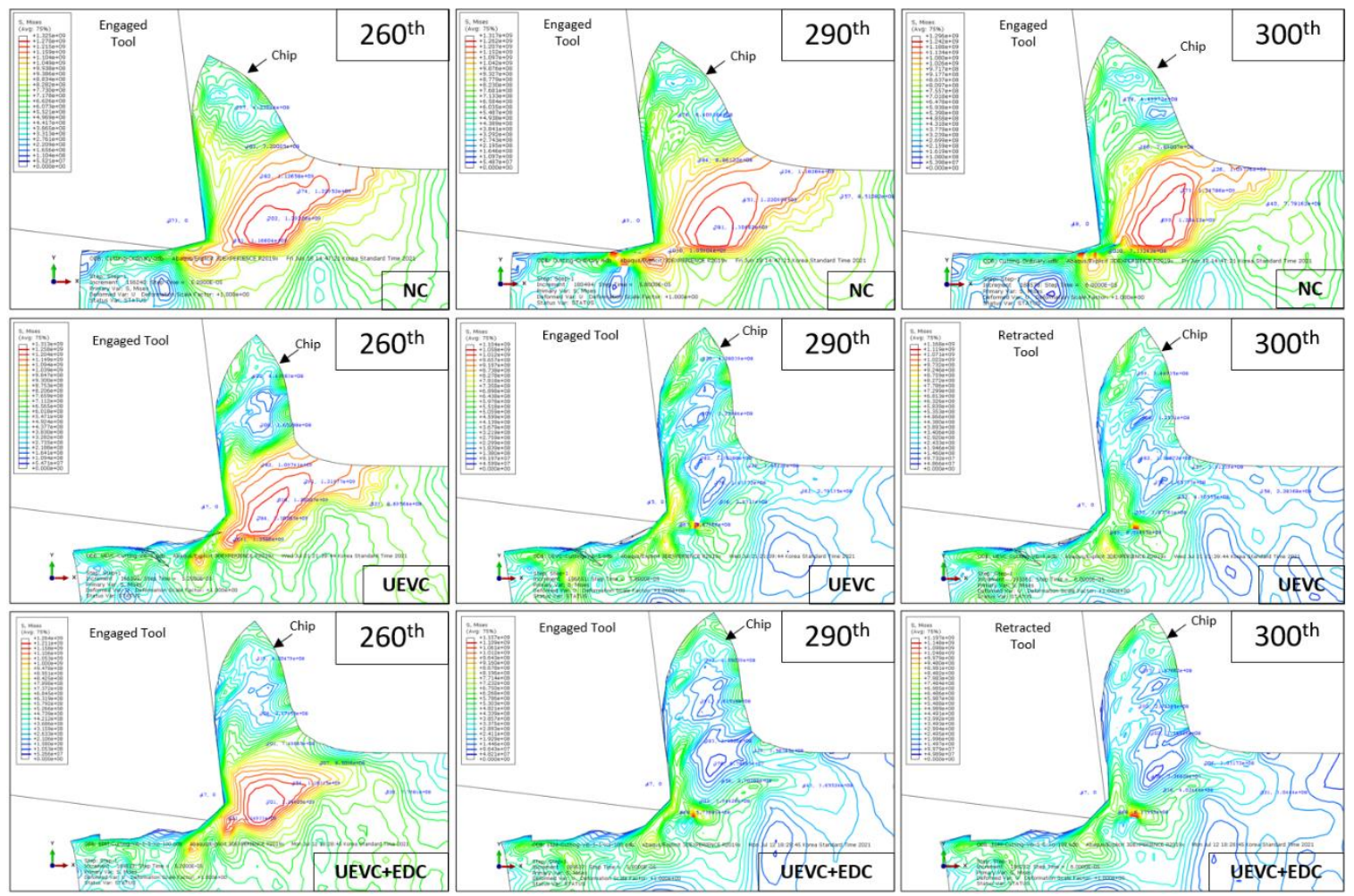

Fig. 6 Numerical von Mises stress contour comparison between NC $\left(\mathrm{V}_{\mathrm{c}}: 2 \mathrm{~m} / \mathrm{s}\right)$, UEVC $\left(\mathrm{V}_{\mathrm{c}}: 2 \mathrm{~m} / \mathrm{s} \& \mathrm{f}_{\mathrm{v}}: 60 \mathrm{kHz}\right)$, and UEVC+EDC ( $\mathrm{V}_{\mathrm{c}}: 2 \mathrm{~m} / \mathrm{s}, \mathrm{f}_{\mathrm{v}}: 60 \mathrm{kHz}, \mathrm{X}_{\mathrm{o}}: 100 \mu \mathrm{m}, \mathrm{V}_{\mathrm{d}}: 220 \mathrm{~V}, \mathrm{R}: 40$ $\mu \mathrm{m})$

Fig. 6 compares the von Mises stress contour of NC, UEVC, and UEVC+EDC. Frames 260,290 , and 300 are presented in Fig. 6 . The maximum stress in NC was concentrated in the main shear deformation with a red color, and the maximum stress was approximately 1,325 MPa (260), 1,317 MPa (290), and 1,296 MPa (300), respectively. It is relatively constant stress in the case of the NC method. In the case of UEVC, the von Mises stress concentrated in the main shear zone decreased when the tool started to leave the main shear zone, as shown in Fig. 6. In addition, by adding EDC in the UEVC, the contour showed a decrease in stress on the main shear zone in the blue region during tool retraction. EDC indicated a decrease in von Mises stress.

Fig. 7 compares the temperature contour of NC, UEVC, and UEVC+EDC, showing frames 260, 290, and 300. In the case of NC, the temperature in the shear deformation zone was constant at approximately $230-240{ }^{\circ} \mathrm{C}$, as shown in Fig. 7. In the case of UEVC, 
Numerical Analysis in Ultrasonic Elliptical Vibration Assisted Cutting (UEVC) Combined with Electrical Discharge Cutting (EDC) for Ti6Al4V

the temperature in the shear deformation zone was higher than that in NC. During tool retraction, as shown in frame 300, the temperature in the shear deformation zone in UEVC was still higher than that in NC. The temperature ranged from 240 to $270^{\circ} \mathrm{C}$, which indicates that the UEVC has a better material removal rate because of the enhanced relative cutting and increased nominal cutting depth, which correlated with the elevated temperature in the shear deformation zone [80]. In the case of UEVC+EDC, the temperature in the shear deformation zone was higher than that in both NC and UEVC because of the EDC Gaussian plasma spark. The temperature was approximately 500 $630{ }^{\circ} \mathrm{C}$. The Gaussian plasma spark involves the cutting process in the UEVC, and the von Mises in UEVC+EDC (Fig. 6) decreases because of the increasing cutting temperature in the shear deformation zone.

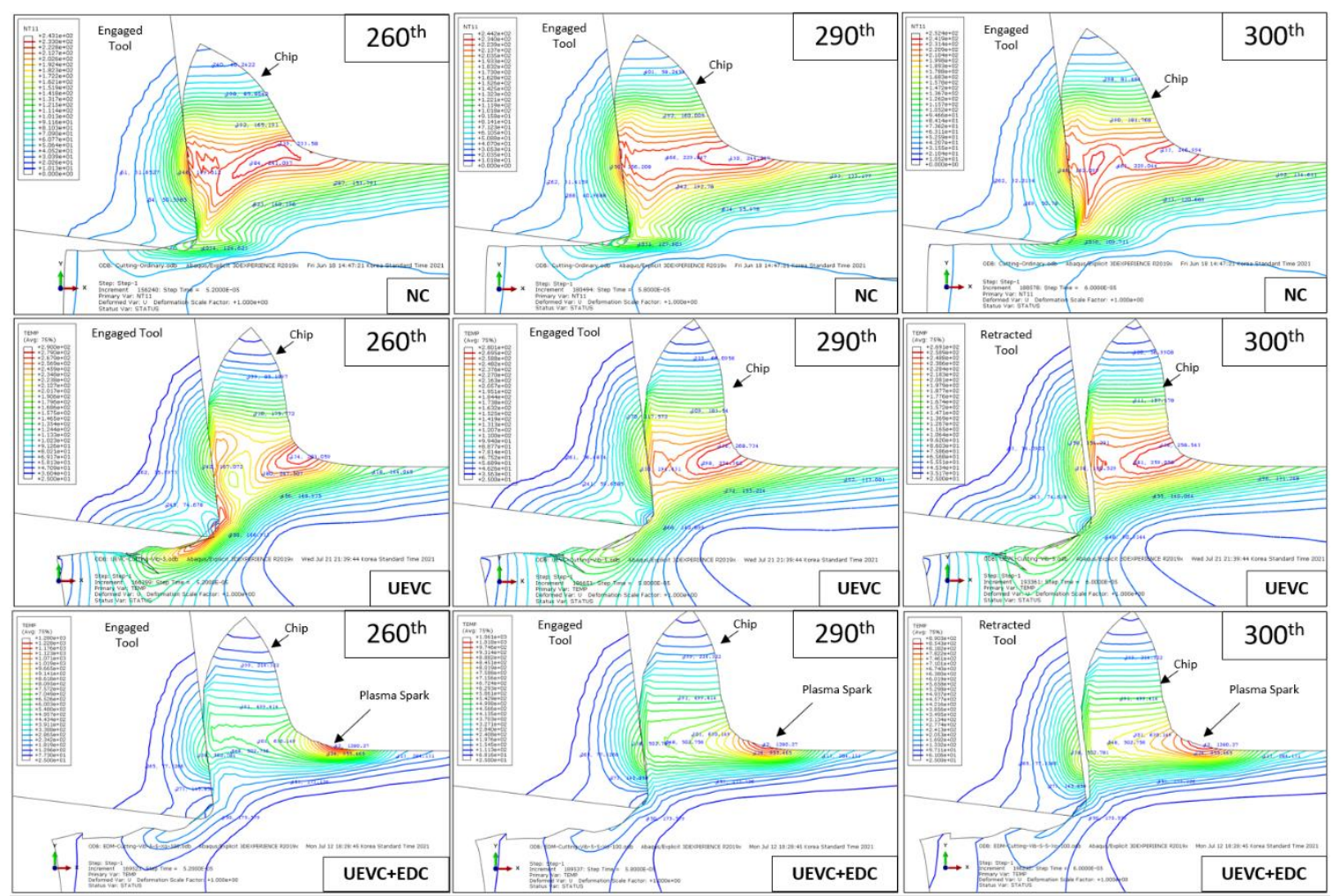

Fig. 7 Numerical temperature contour comparison between NC $\left(\mathrm{V}_{\mathrm{c}}: 2 \mathrm{~m} / \mathrm{s}\right)$, UEVC $\left(\mathrm{V}_{\mathrm{c}}: 2\right.$ $\left.\mathrm{m} / \mathrm{s} \& \mathrm{f}_{\mathrm{v}}: 60 \mathrm{kHz}\right)$, and UEVC+EDC ( $\left.\mathrm{V}_{\mathrm{c}}: 2 \mathrm{~m} / \mathrm{s}, \mathrm{f}_{\mathrm{v}}: 60 \mathrm{kHz}, \mathrm{X}_{\mathrm{o}}: 100 \mu \mathrm{m}, \mathrm{V}_{\mathrm{d}}: 220 \mathrm{~V}, \mathrm{R}: 40 \mu \mathrm{m}\right)$

\subsection{Numerical von Mises Stress and Cutting Temperature Element}

Figs. 9, 10, 11, and 12 present the numerical result of the von Mises and the temperature at surface element 39. Element 39 was selected because it is located at the top of the workpiece surface, as shown in Fig. 8. Fig. 9 compares the stress and temperature of the three different cutting methods (NC, UEVC, and UEVC+EDC). In the NC method (Fig. 9(a)), the stress and temperature increase as the main cutting zone is approached. The maximum stress and temperature indicate that element 39 is close to 
Numerical Analysis in Ultrasonic Elliptical Vibration Assisted Cutting (UEVC) Combined with Electrical Discharge Cutting (EDC) for Ti6Al4V

the main cutting zone. The stress and temperature then decrease as element 39 leaves the main cutting zone. Hence, element 39 becomes a deformed chip. This trend of the stress and temperature at a specific element location for the NC process shows a similar trend to Ayed et al. [81].

The UEVC driven at $40 \mathrm{kHz}$ (Fig. 9 (b)) produced a fluctuated stress and temperature pattern due to the presence of the tool vibration. Therefore, during the retraction mode, the stress was relieved and decreased considerably [82]. In addition, in the UEVC+EDC method (Fig. 9 (c)), due to the presence of the pulsed Gaussian discharged plasma, element 39 experiences considerable thermal load before entering vibrationassisted cutting mode; thus, the temperature increases considerably to $1200^{\circ} \mathrm{C}$, and the stress element decreases. This thermal loading effect also increases the temperature element to $600^{\circ} \mathrm{C}$. Thus, the stress element decreases significantly. Fig. 9 (d) summarizes the average stress and temperature element; the UEVC+EDC increases the temperature element and decreases the stress element compared to the UEVC and NC methods.

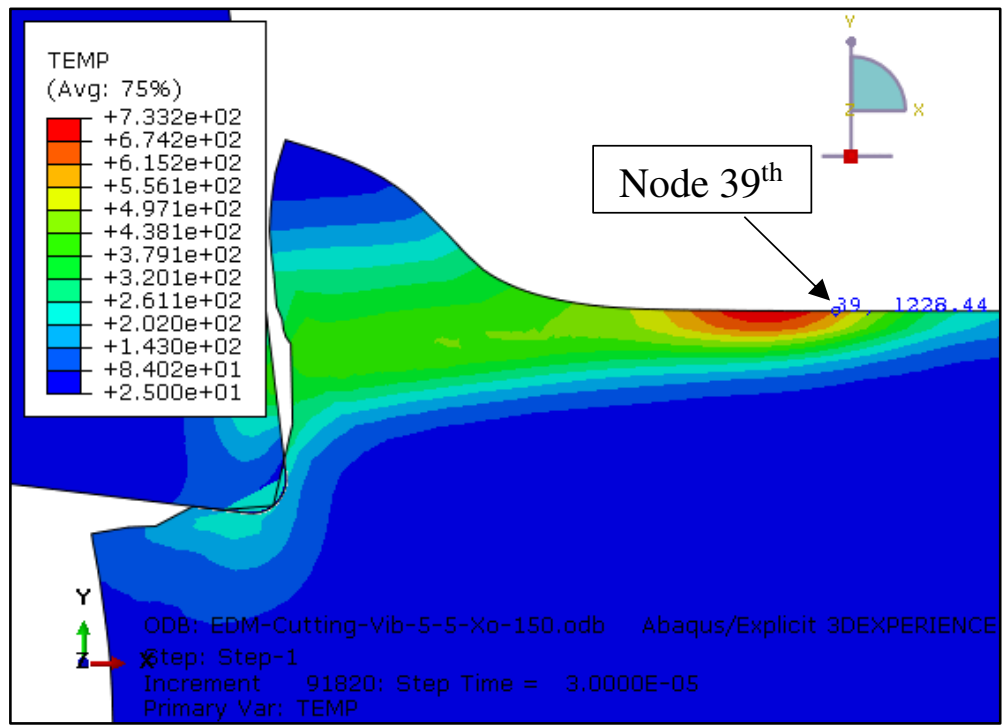

Fig. 8 Location of Node 39 in the post-processor FEA result in the middle of the top surface workpiece

Fig. 10 presents the von Mises stress and temperature element 39 due to the different distance pulse $X_{0}$ between $50 \mu \mathrm{m}$ and $200 \mu \mathrm{m}$. Fig. 10(a) shows the UEVC method at a vibration frequency of $60 \mathrm{kHz}$ for a comparison with UEVC+EDC. The maximum temperature of element 39 was approximately $350{ }^{\circ} \mathrm{C}$. Overall, it becomes $212.53{ }^{\circ} \mathrm{C}$. Figs. 10 (b), 10(c), 10(d), and 10(e) show the stress and temperature element 39 when the distance pulse $X_{o}=50 \mu \mathrm{m}, 100 \mu \mathrm{m}, 150 \mu \mathrm{m}$, and $200 \mu \mathrm{m}$, respectively. When $X_{0}=50 \mu \mathrm{m}$ in UEVC+EDC, temperature element 39 increases significantly compared to the UEVC, as shown in Fig. 10(b). On the other hand, the maximum temperature was lowest compared to other distance pulses because the Gaussian heat flux was close to the deformed chip. Therefore, the temperature was distributed uniformly around the deformed chip during cutting. The average stress was lowest compared to other distance pulses. By increasing the distance pulses, the maximum temperature pattern showed a 
Numerical Analysis in Ultrasonic Elliptical Vibration Assisted Cutting (UEVC) Combined with Electrical Discharge Cutting (EDC) for Ti6Al4V

shift to the left because of the relative position of the element to the Gaussian heat flux. Bringing the Gaussian heat flux to as close to the main shear deformation as possible could be more effective in minimizing the average stress, as shown in Fig. 10(f). As shown in Fig. 10(f), the UEVC+EDC effectively decreased the average von Mises stress compared to the UEVC.

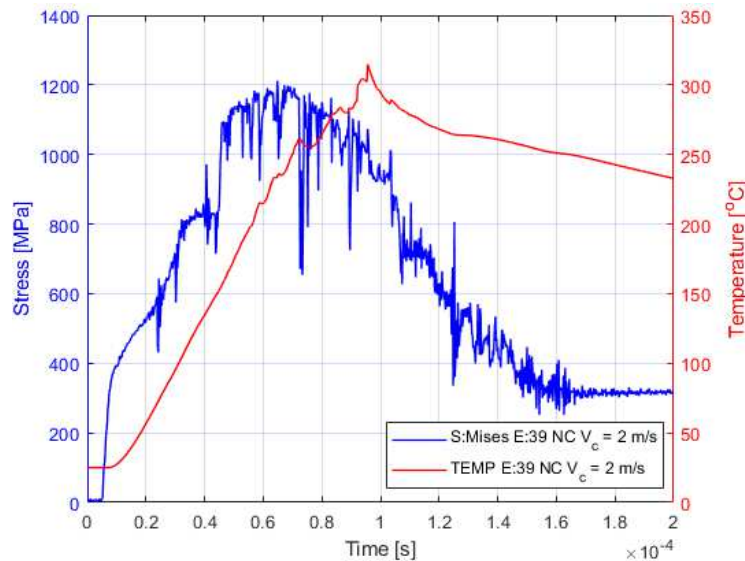

(a)

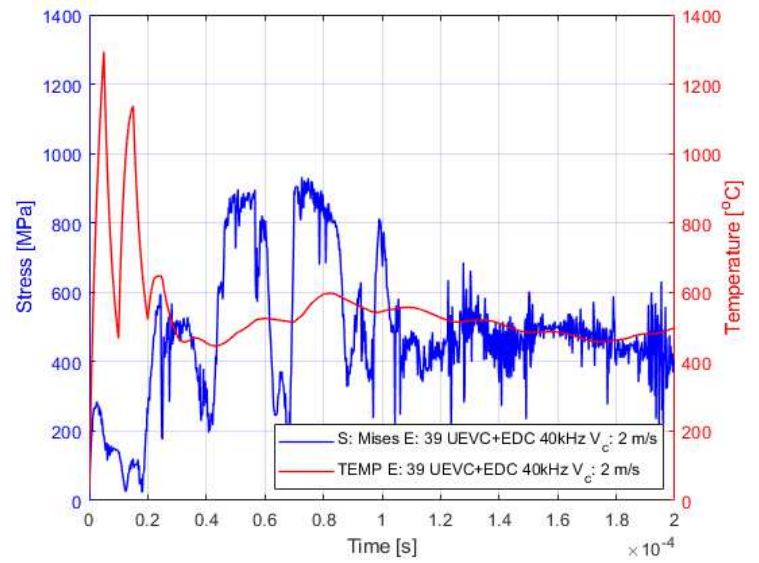

(c)

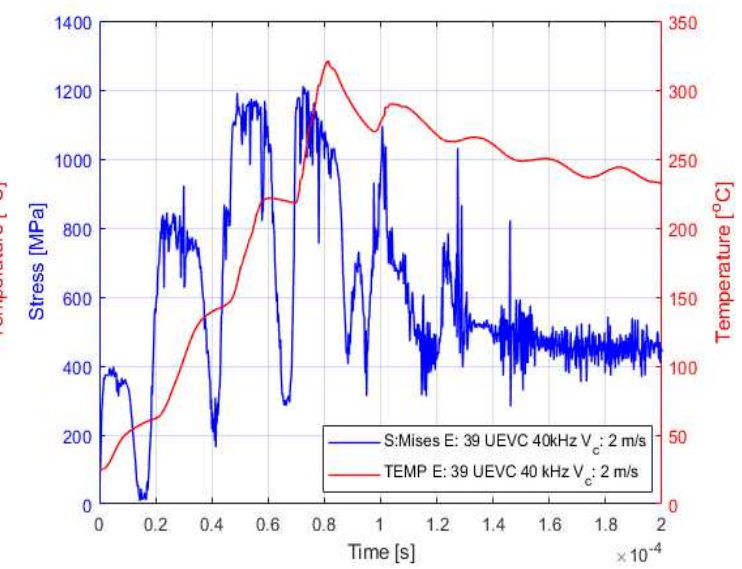

(b)

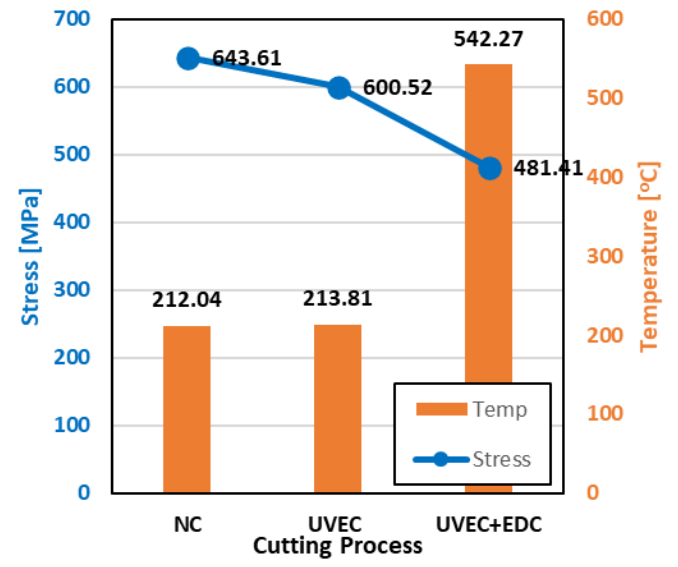

(d)

Fig. 9 Comparison of the von Mises stress and surface element temperature pattern at $\mathrm{E}$ : 39 as a function of the cutting time for the three different cutting methods. (a) NC ( $\mathrm{V}_{\mathrm{c}}: 2$ $\mathrm{m} / \mathrm{s})$, (b) UEVC ( $\left.\mathrm{V}_{\mathrm{c}}: 2 \mathrm{~m} / \mathrm{s} \& \mathrm{f}_{\mathrm{v}}: 40 \mathrm{kHz}\right)$, and (c) UEVC+EDC $\left(\mathrm{V}_{\mathrm{c}}: 2 \mathrm{~m} / \mathrm{s}, \mathrm{f}_{\mathrm{v}}: 40 \mathrm{kHz}, \mathrm{X}_{\mathrm{o}}: 200\right.$ $\left.\mu \mathrm{m}, V_{d}: 200 \mathrm{~V}, \mathrm{R}: 40 \mu \mathrm{m}\right)$, (d) average value 
Numerical Analysis in Ultrasonic Elliptical Vibration Assisted Cutting (UEVC) Combined with Electrical Discharge Cutting (EDC) for Ti6Al4V

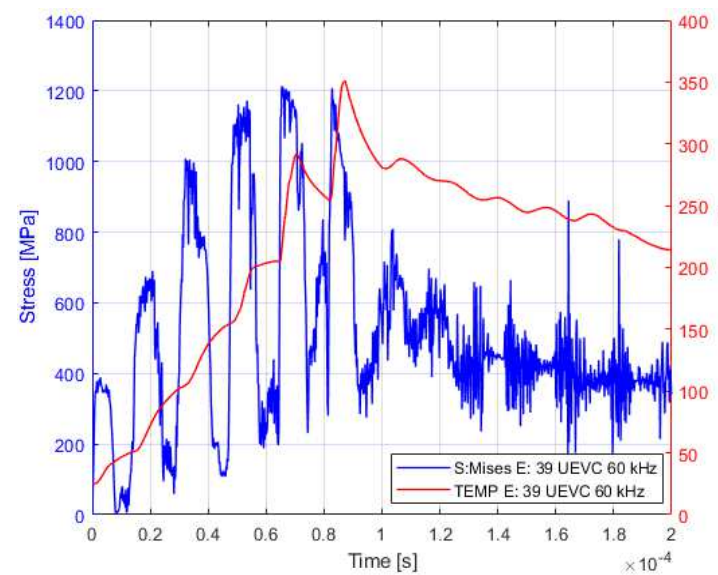

(a)

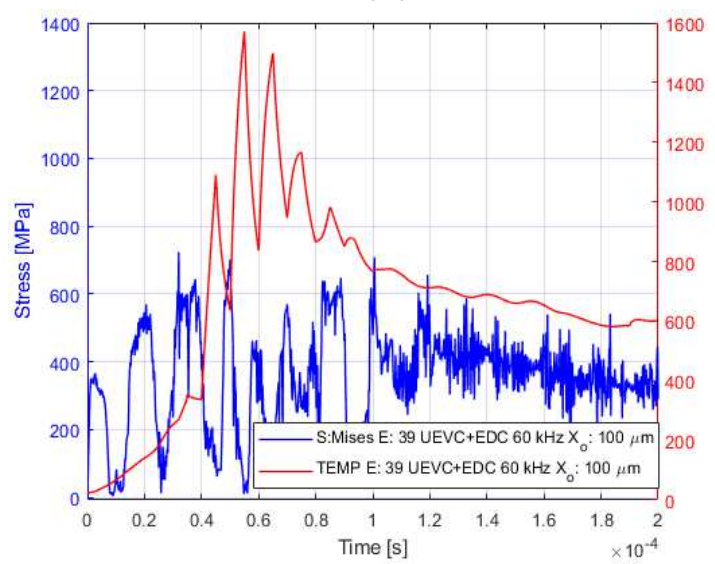

(c)

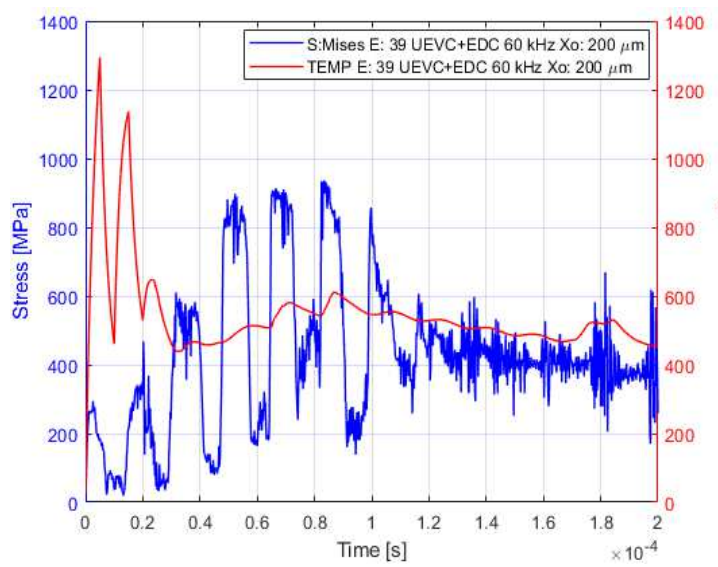

(e)

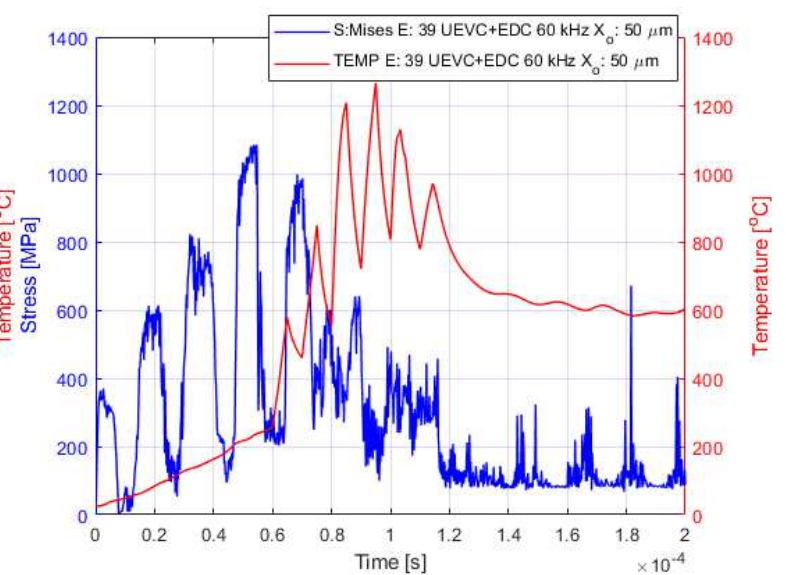

(b)

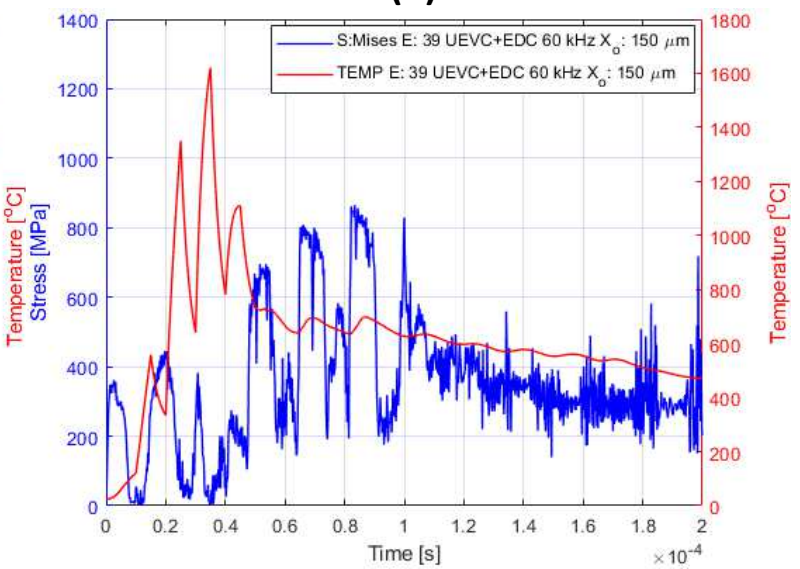

(d)

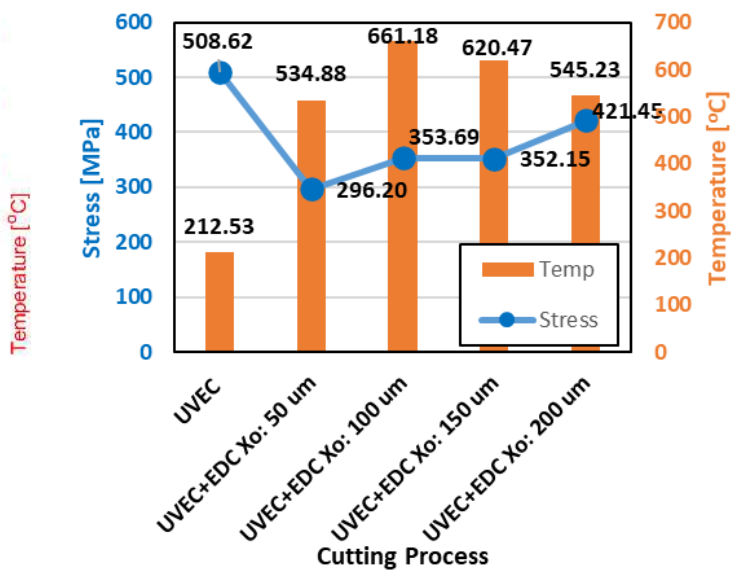

(f)

Fig. 10 Effect of the distance of the pulse $X_{0}$, von Mises stress and surface element temperature pattern at $E: 39$ as a function of the cutting time at a constant $V_{c}: 2 m / s, f_{v}$ : $60 \mathrm{kHz}, \mathrm{D}_{\mathrm{h}}: 100 \mu \mathrm{m}, \mathrm{V}_{\mathrm{d}}: 220 \mathrm{~V}$, and R: $40 \mu \mathrm{m}$. (a) UEVC, (b) UEVC+EDC (X: $50 \mu \mathrm{m}$ ), (c)

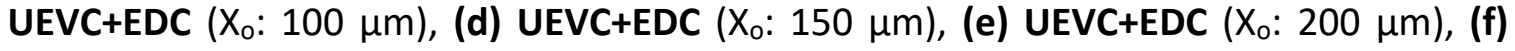
average value 
Numerical Analysis in Ultrasonic Elliptical Vibration Assisted Cutting (UEVC) Combined with Electrical Discharge Cutting (EDC) for Ti6Al4V

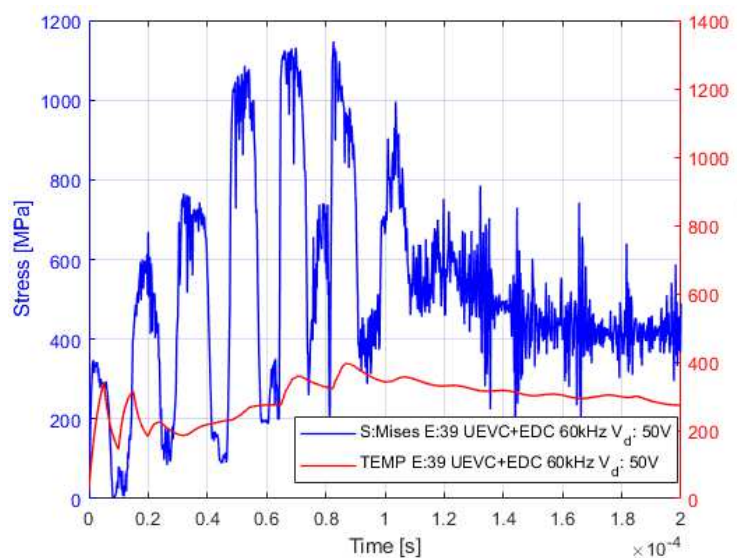

(a)

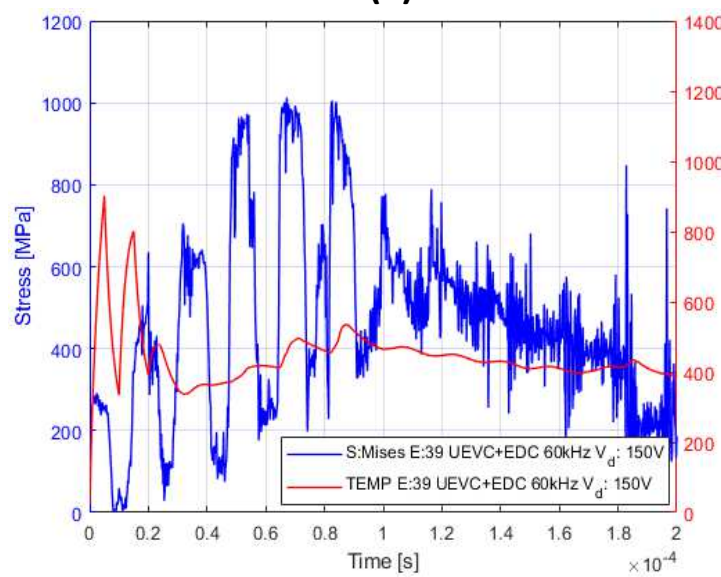

(c)

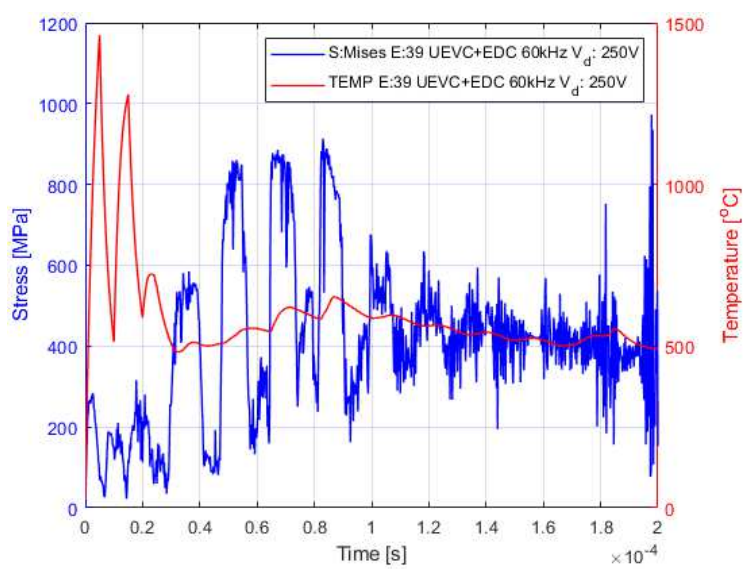

(e)

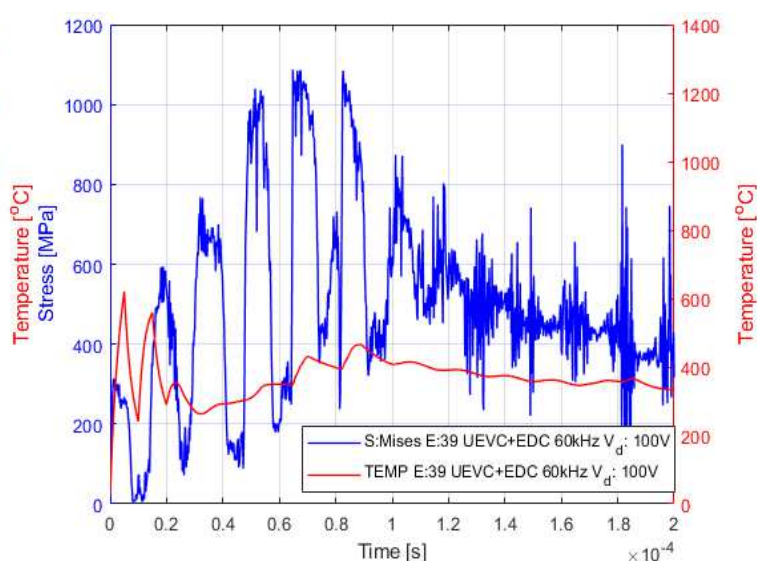

(b)

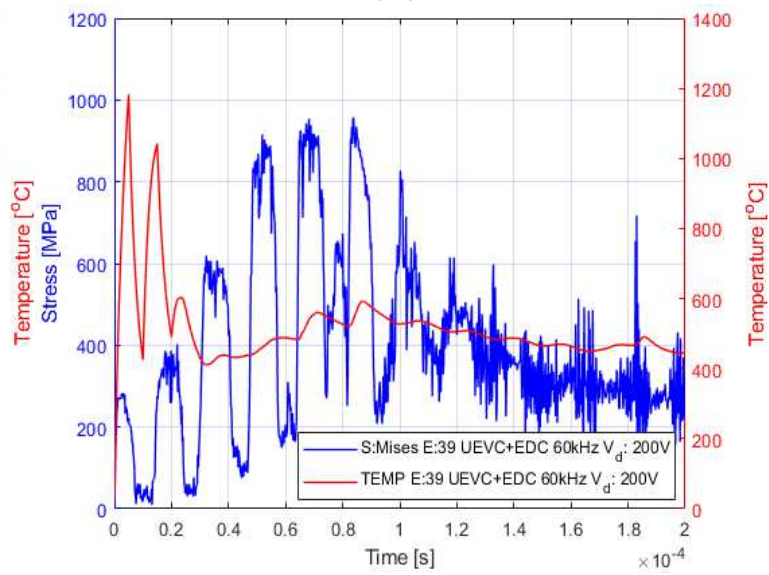

(d)

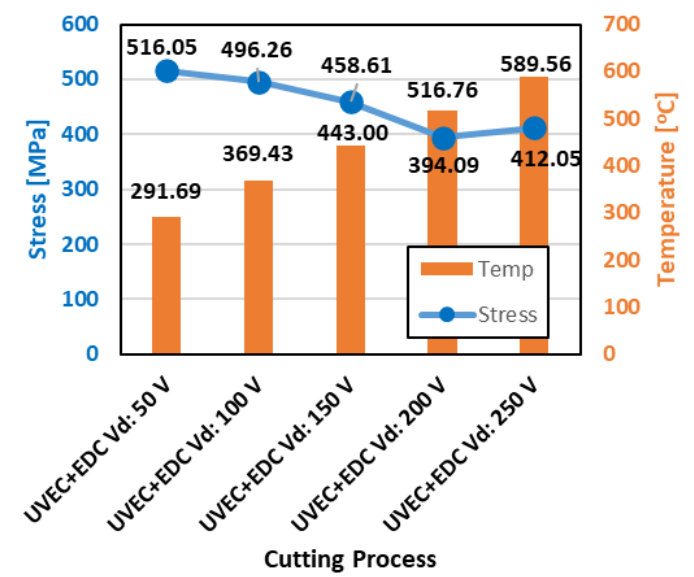

(f)

Fig. 11 Effect of the discharge voltage $V_{d}$, von Mises stress, and surface element temperature pattern at $E: 39$ as a function of the cutting time at a constant $V_{c}: 2 m / s, f_{v}$ : $60 \mathrm{kHz}, \mathrm{D}_{\mathrm{h}}: 100 \mu \mathrm{m}, \mathrm{Xo}: 200 \mu \mathrm{m}$, and R: $40 \mu \mathrm{m}$. (a) UEVC+EDC (V: $\left.50 \mathrm{~V}\right)$, (b) UEVC+EDC $\left(V_{d}: 100\right.$ V), (c) UEVC+EDC (V $V_{d}: 150$ V), (d) UEVC+EDC (V: 200 V), (e) UEVC+EDC (V 250 $\mathrm{V})$, (f) average value 
Numerical Analysis in Ultrasonic Elliptical Vibration Assisted Cutting (UEVC) Combined with Electrical Discharge Cutting (EDC) for Ti6Al4V

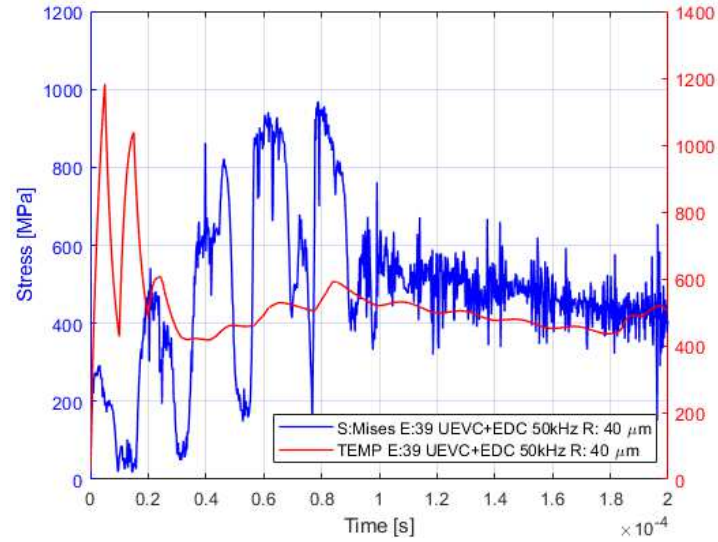

(a)

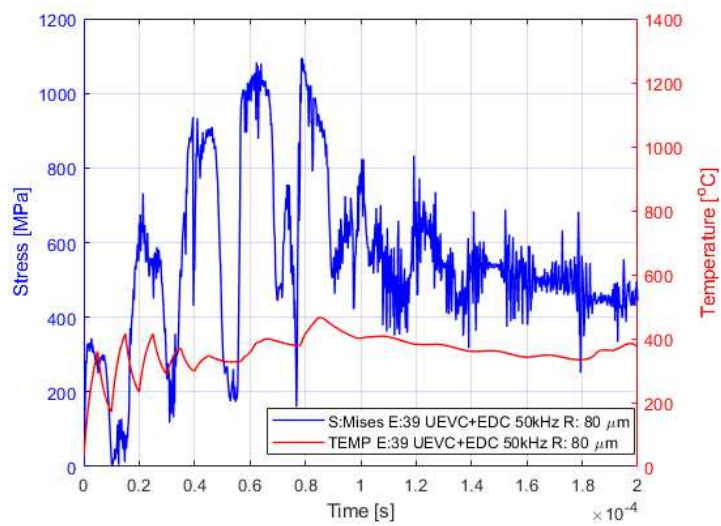

(c)

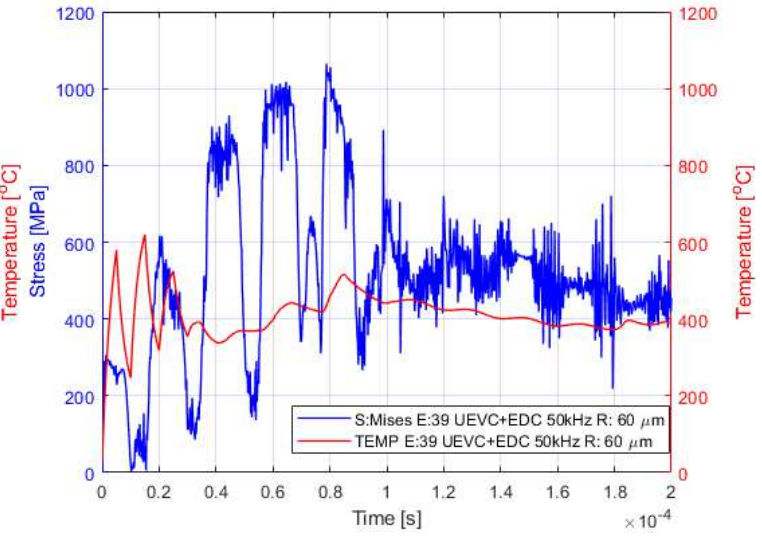

(b)

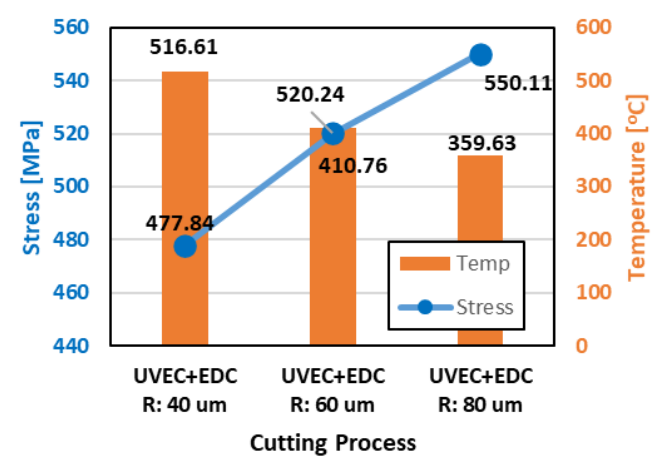

(d)

Fig. 12 Effect of the discharged pulse radius $\mathrm{R}$, von Mises stress, and surface element temperature pattern at $E: 39$ as a function of the cutting time at a constant $V_{c}: 2 m / s, f_{v}$ : $60 \mathrm{kHz}, \mathrm{D}_{\mathrm{h}}: 100 \mu \mathrm{m}, \mathrm{X}_{\mathrm{o}}: 200 \mu \mathrm{m}$, and $\mathrm{V}_{\mathrm{d}}: 200 \mathrm{~V}$. (a) UEVC+EDC (R: $\left.40 \mu \mathrm{m}\right)$, (b) UEVC+EDC (R: $60 \mu \mathrm{m})$, (c) UEVC+EDC (R: $80 \mu \mathrm{m})$, (d) average value

Fig. 11 presents the von Mises stress and temperature of element 39 by the effect of different discharge voltages from $50 \mathrm{~V}$ to $250 \mathrm{~V}$ for the UEVC+EDC method. Figs. 11 (a), 11(b), 11(c), 11(d), and 11(e) show the von Mises stress and temperature of element 39 by discharge voltages of $50 \mathrm{~V}, 100 \mathrm{~V}, 150 \mathrm{~V}, 200 \mathrm{~V}$, and $250 \mathrm{~V}$, respectively. The numerical cutting condition was carried out with a constant $X_{0}=200 \mu \mathrm{m}$ and $\mathrm{R}=40 \mu \mathrm{m}$. Based on Eq. 7 of the pulsed Gaussian heat flux, the heat energy increased with increasing discharged voltage because the maximum peak temperature will increase for pulsed Gaussian heat flux. As shown in Fig. 11, the maximum peak temperature will increase from $300{ }^{\circ} \mathrm{C}$ to nearly $1500{ }^{\circ} \mathrm{C}$ when the discharge voltage is increased from $50 \mathrm{~V}$ to 250 $\mathrm{V}$. The von Mises stress decreased with increasing peak temperature. As shown in Fig. $11(f)$, the average value for stress and temperature was taken; the stress decreased with increasing average temperature. On the other hand, the stress increased slightly at $\mathrm{V}=$ $250 \mathrm{~V}$, possibly because the stress remained steady in the deformed chip ( $\approx 400 \mathrm{MPa}$ ) in the numerical calculation. Despite this, the stress can be decreased by approximately 200 MPa when the temperature increases drastically (Fig. 11(e)). 
Numerical Analysis in Ultrasonic Elliptical Vibration Assisted Cutting (UEVC) Combined with Electrical Discharge Cutting (EDC) for Ti6Al4V

Fig. 12 shows the von Mises stress and temperature of element 39 by the effect of different discharged radii of the pulsed Gaussian heat flux from $40 \mu \mathrm{m}$ to $80 \mu \mathrm{m}$. Based on Eq. 7, the heat flux decreased with increasing the discharged plasma radius $\mathrm{R}$ because the discharged voltage and current were constant at $\mathrm{V}=200 \mathrm{~V}$ and $\mathrm{I}=1 \mathrm{~A}$. As shown in Fig. 12, when the discharged radius was increased, the maximum temperature discharge plasma at element 39 became weaker, as observed in Figs. 12(a), 12(b), and 12(c). The maximum temperature of element 39 decreased from approximately $1200{ }^{\circ} \mathrm{C}$ to $400{ }^{\circ} \mathrm{C}$. Thus, it yielded higher von Mises stress. Fig. 12 (d) presents the average value; $R=40 \mu \mathrm{m}$ produced a more effective decrease in the average von Mises stress because of the higher average temperature.

\subsection{Numerical Cutting Forces and Comparison}

Fig. 13 compares the numerical cutting forces $\left(F_{c}\right.$ and $\left.F_{t}\right)$ of the three methods (NC, UEVC, and UEVC+EDC). Figs. 13(a), 13(b), and 13(c) show the cutting forces pattern of NC, UEVC, and UEVC+EDC, respectively. The vibration frequency of $50 \mathrm{kHz}$ was selected for UEVC and UEVC+EDC because a clear fluctuating cutting forces pattern was observed from $S . R>1$. $F_{c}$ represents the principal force pattern along the $x$-direction by blue color, and $F_{t}$ represents the thrust force pattern along the $y$-direction by red color.

In the case of the NC method, the cutting forces increased gradually and achieved a steady-state at $0.8 \mathrm{~s}$ then it dropped to zero after $1.6 \mathrm{~s}$, as shown in Fig. 12(a). A fracture developed at the end of the cutting process because the deformed chip in numerical analysis was left out of the main cutting zone, as shown in Fig 13(d). The deformed chip remained at the end of the cutting process in the UEVC and UEVC+EDC method. Although no fracture propagation occurred in UEVC+EDC (Fig. 13(d)), fracture propagation in UEVC began to grow at the end of cutting in frame 1000. Therefore, the cutting forces trend decreases but does not achieve a zero level in both UEVC and UEVC+EDC because the deformed chip remains at the end of the cutting process due to tool vibration motion.

The cutting forces in UEVC and UEVC+EDC typically fluctuate due to the vibration mechanism of the tool with periodically tool engaging and the tool disengaging into the main shear deformation zone. Moreover, the maximum peak of the cutting force $F_{c}$ in the UEVC+EDC decreased slightly compared to the maximum cutting force $F_{c}$ in the UEVC. Evidently, the cutting force $F_{c}$ can be reduced by adding EDC to UEVC. On the other hand, EDC does not decrease the thrust force, and $F_{t}$ shows a similar pattern with UEVC alone.

Fig. 14 shows the cutting forces in the UEVC+EDC method by the effect of the vibration frequencies. The vibration frequencies were varied from $20 \mathrm{kHz}$ to $60 \mathrm{kHz}$. Figs. 14(a), 14(b), 14(c), 14(d), and 14(e) show the cutting forces at vibration frequencies of 20 $\mathrm{kHz}, 30 \mathrm{kHz}, 40 \mathrm{kHz}, 50 \mathrm{kHz}$, and $60 \mathrm{kHz}$, respectively. The tool vibrates more by increasing the vibration frequency from 20 to $60 \mathrm{kHz}$. Because $S . R<1$ at a vibration frequency of 20 $\mathrm{kHz}$ (Fig. 14(a)) and $30 \mathrm{kHz}$ (Fig. 14(b)), there were no significant fluctuations of the cutting force pattern. This indicates that the tool still contacts the main cutting zone continuously with less fluctuating vibrations. Furthermore, S.R $>1$ at higher frequencies, such as $40 \mathrm{kHz}$ (Fig. 14(c)), $50 \mathrm{kHz}$ (Fig. 14(d)), and $60 \mathrm{kHz}$ (Fig. 14(e)). Therefore, the cutting forces begin to fluctuate, which indicates the tool leaving the main cutting zone, and UEVC+EDC is 
Numerical Analysis in Ultrasonic Elliptical Vibration Assisted Cutting (UEVC) Combined with Electrical Discharge Cutting (EDC) for Ti6Al4V

more effective in decreasing the average cutting force by the higher frequency if $S . R>1$ is considered.

Fig. 15 summarizes the average cutting force for UEVC+EDC with different distance plasma pulses $X_{o}=50-200 \mu \mathrm{m}$ (Fig. 15(a)), different discharge voltages $V_{d}=150-250 \mathrm{~V}$ (Fig. 15(b)), and different plasma radii $\mathrm{R}=40-80 \mu \mathrm{m}$ (Fig. 15(c)). The average cutting forces for NC and UEVC are also included for comparison. According to the results, the average cutting forces decreased in UEVC compared to NC due to active tool vibration. By adding the EDC method to UEVC, the cutting forces were improved slightly, as indicated by marginally lower cutting forces at various vibration frequencies, as shown in Fig. 15(a) and Fig. 15(b). Lowering plasma spark distance $X_{o}$ and increasing discharge voltage $V_{d}$ will help decrease cutting force, especially the principal force $F_{c}$. Fig. 15(c) presents a contradictory result; the cutting forces increased at a high plasma radius. As mentioned in Chapter 4.2, the heat flux becomes weaker by increasing the plasma radius.
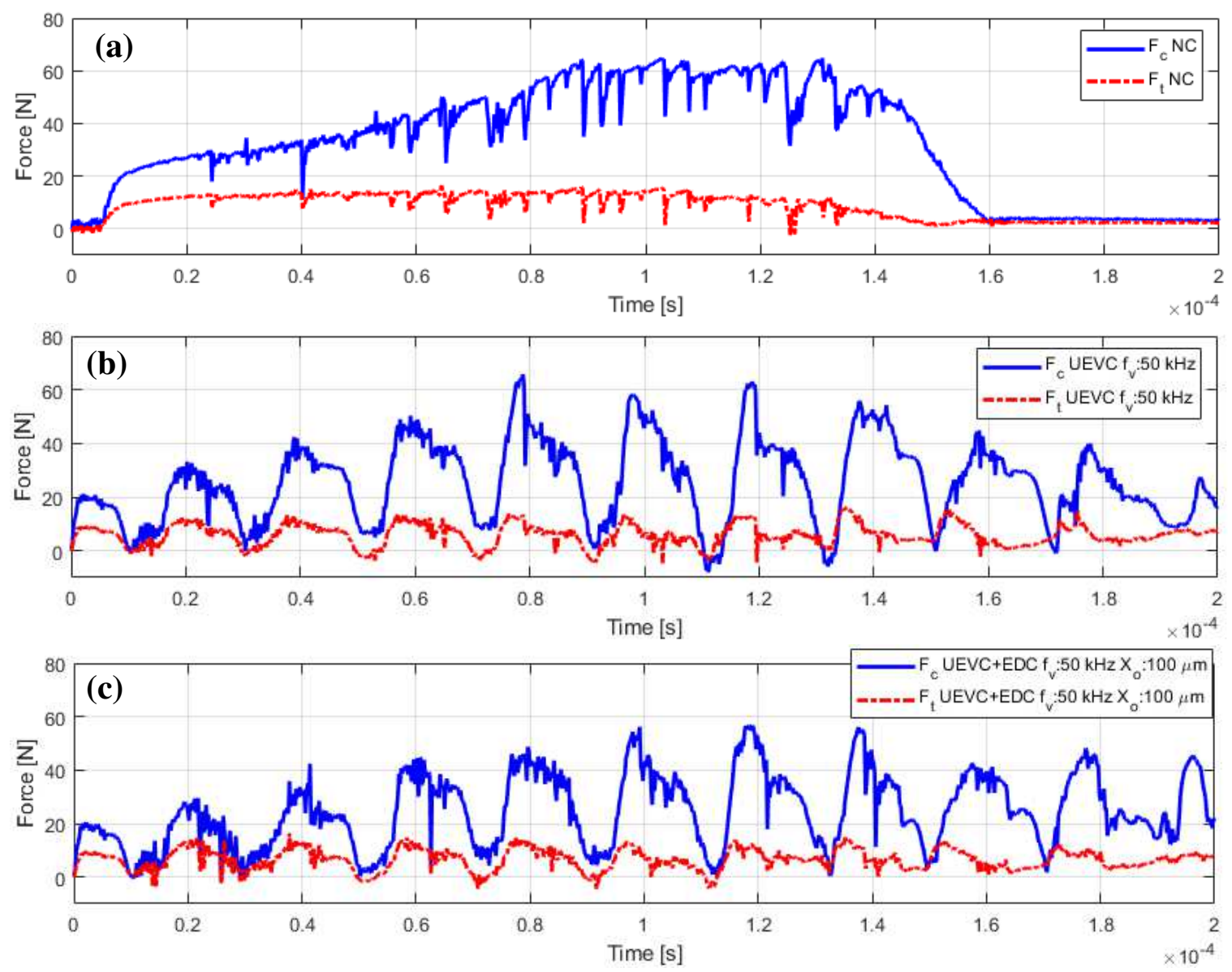
Numerical Analysis in Ultrasonic Elliptical Vibration Assisted Cutting (UEVC) Combined with Electrical Discharge Cutting (EDC) for Ti6Al4V

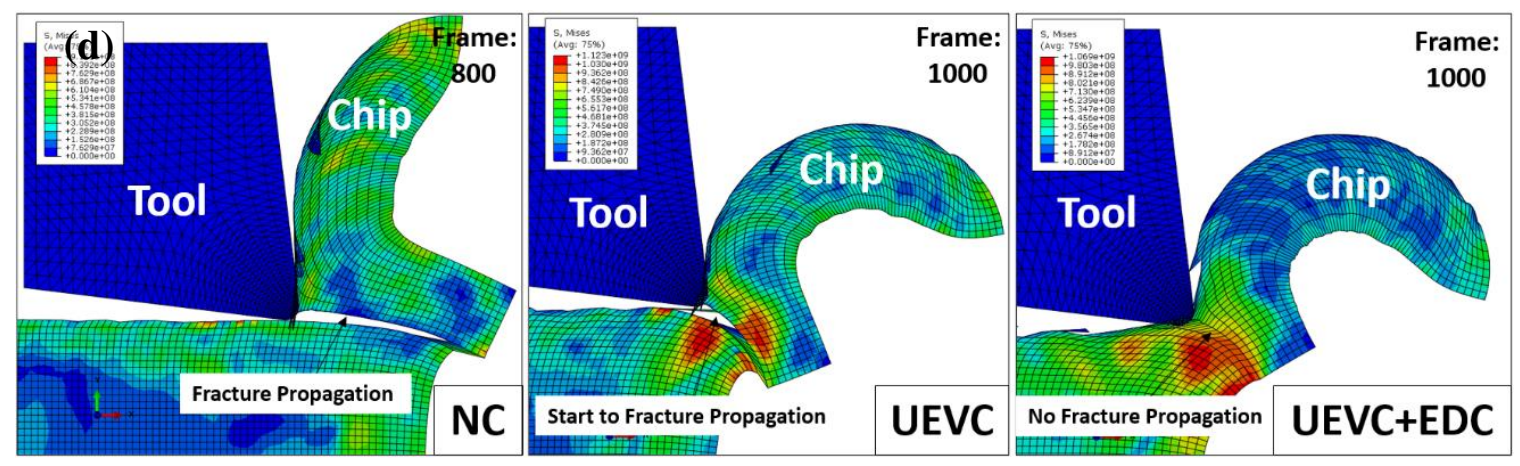

Fig. 13 Numerical cutting force for three different methods, (a) NC ( $\left.\mathrm{V}_{\mathrm{c}}: 2 \mathrm{~m} / \mathrm{s}\right)$, (b) UEVC $\left(\mathrm{V}_{\mathrm{c}}: 2 \mathrm{~m} / \mathrm{s} \& \mathrm{f}_{\mathrm{v}}: 50 \mathrm{kHz}\right)$ (c) UEVC+EDC ( $\mathrm{V}_{\mathrm{c}}: 2 \mathrm{~m} / \mathrm{s}, \mathrm{f}_{\mathrm{v}}: 50 \mathrm{kHz}, \mathrm{X}_{\mathrm{o}}: 100 \mu \mathrm{m}, \mathrm{V}_{\mathrm{d}}: 220 \mathrm{~V}, \mathrm{R}: 40$ $\mu \mathrm{m}),(\mathrm{d})$ deformed chip at the end of cutting
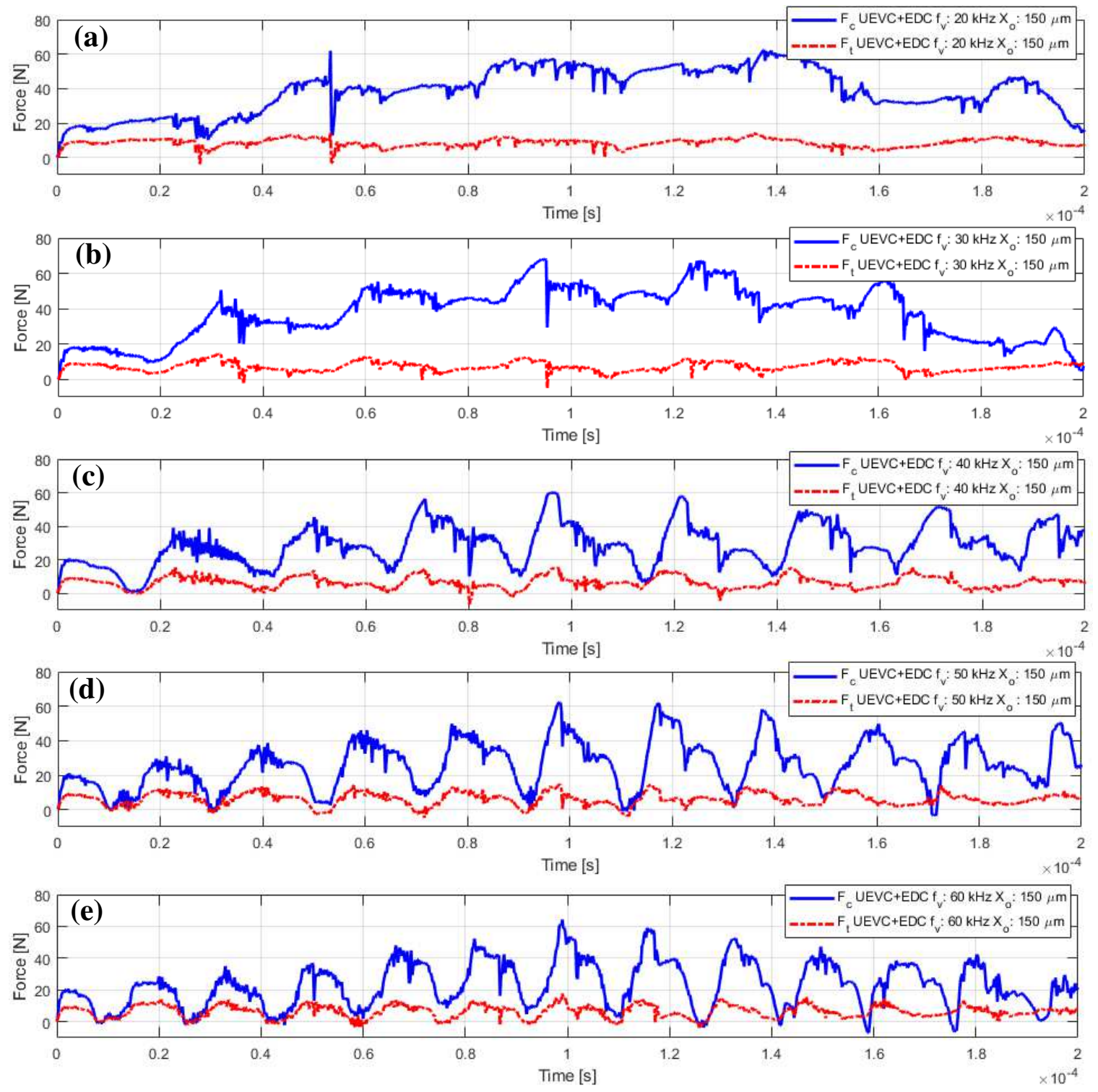
Numerical Analysis in Ultrasonic Elliptical Vibration Assisted Cutting (UEVC) Combined with Electrical Discharge Cutting (EDC) for Ti6Al4V

Fig. 14 Numerical cutting force for UEVC+EDC ( $\left.\mathrm{X}_{\mathrm{o}}: 150 \mu \mathrm{m}, \mathrm{V}_{\mathrm{d}}: 220 \mathrm{~V}, \mathrm{R}: 40 \mu \mathrm{m}\right)$ at different vibration frequencies (a) $f_{v}: 20 \mathrm{kHz}$, (b) $f_{v}: 30 \mathrm{kHz}$, (c) $f_{v}: 40 \mathrm{kHz}$, (d) $f_{v}: 50 \mathrm{kHz}$, (e) $f_{v}: 60 \mathrm{kHz}$

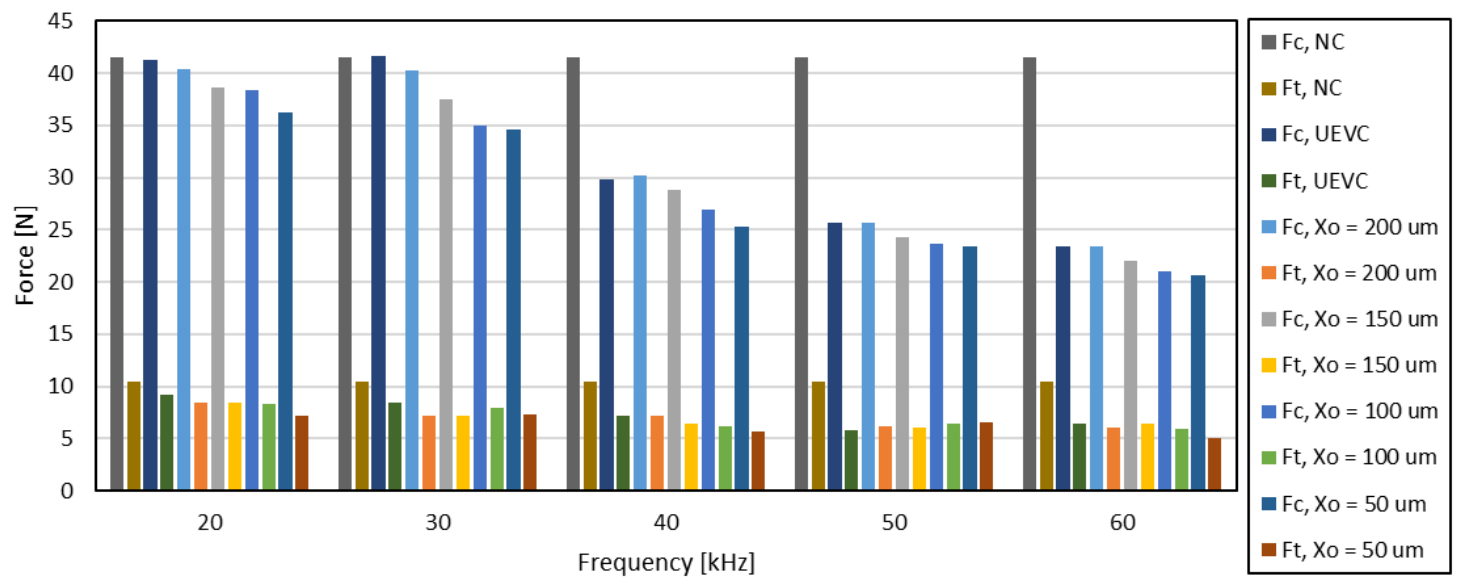

(a) $X_{\circ}: 50-200 \mu m$

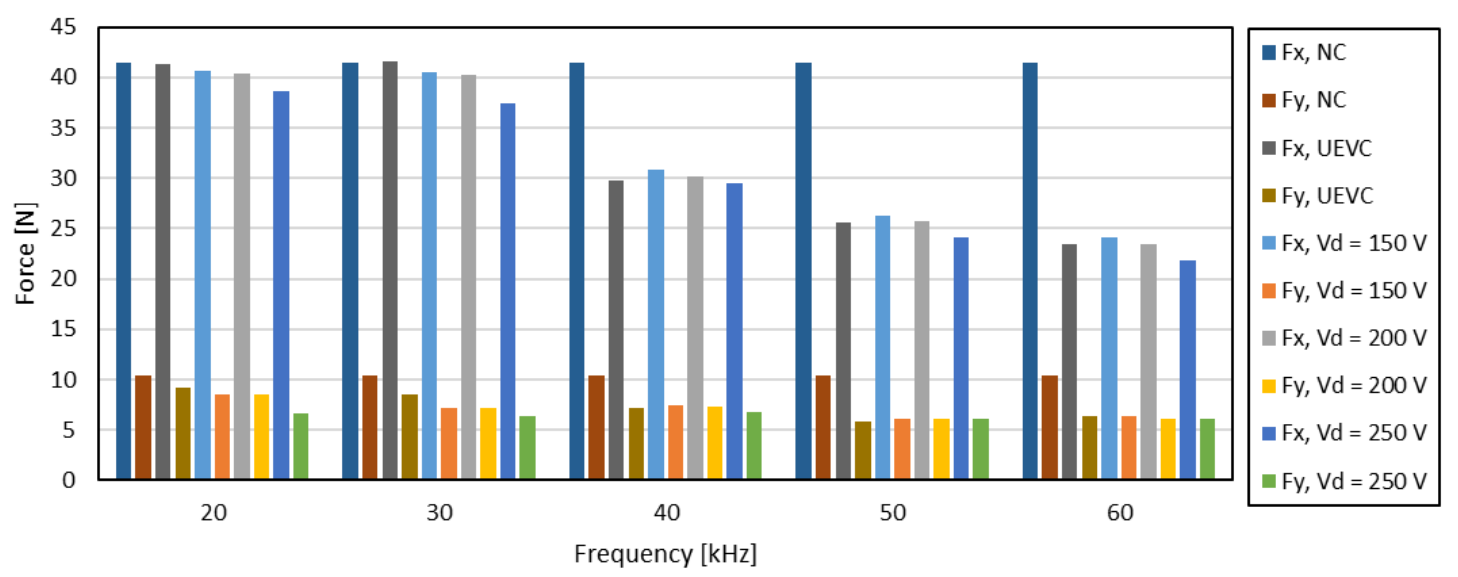

(b) $V_{d}: 150-250 \mathrm{~V}$

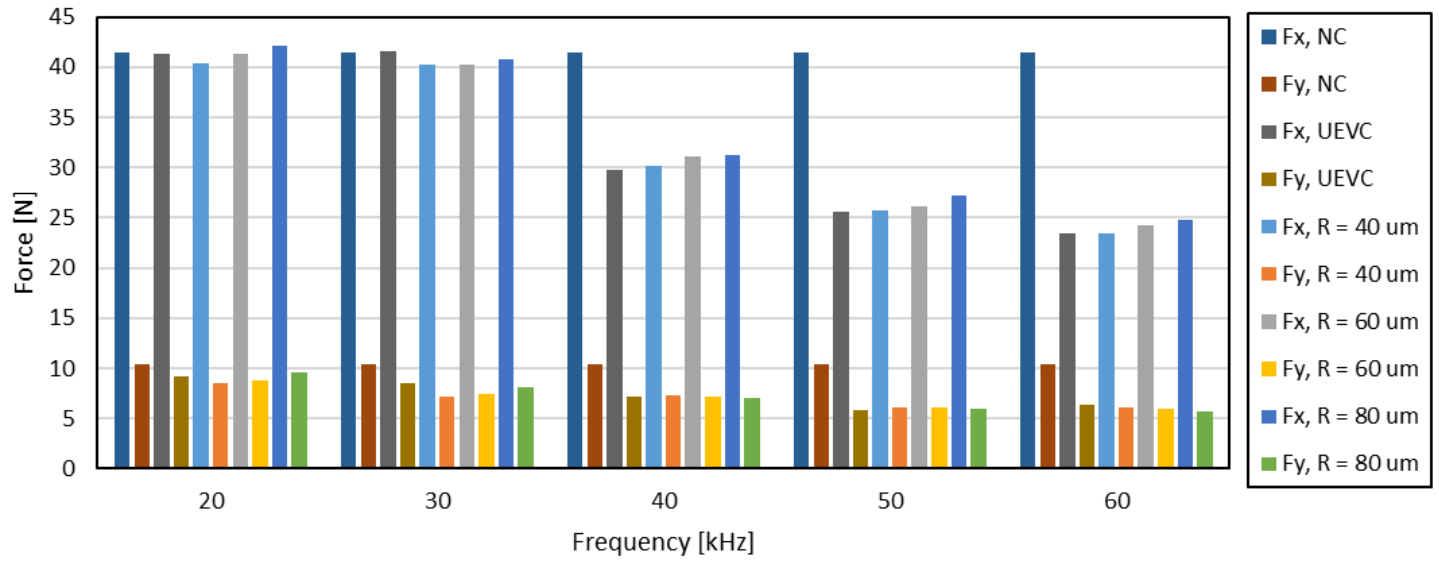

(c) R: $40-80 \mu \mathrm{m}$ 
Numerical Analysis in Ultrasonic Elliptical Vibration Assisted Cutting (UEVC) Combined with Electrical Discharge Cutting (EDC) for Ti6Al4V

Fig. 15 Average numerical forces for $F_{c}$ and $F_{t}$ in the UEVC+EDC method at $f_{v}=20-50 \mathrm{kHz}$ compared to the NC and UEVC method, (a) with different distance pulse $X_{0}=50-200 \mu \mathrm{m}$ (b) with different discharge voltages $V_{d}=150-250 \mathrm{~V}$ (c) with different plasma radii $R=$ 40-80 $\mu \mathrm{m}$

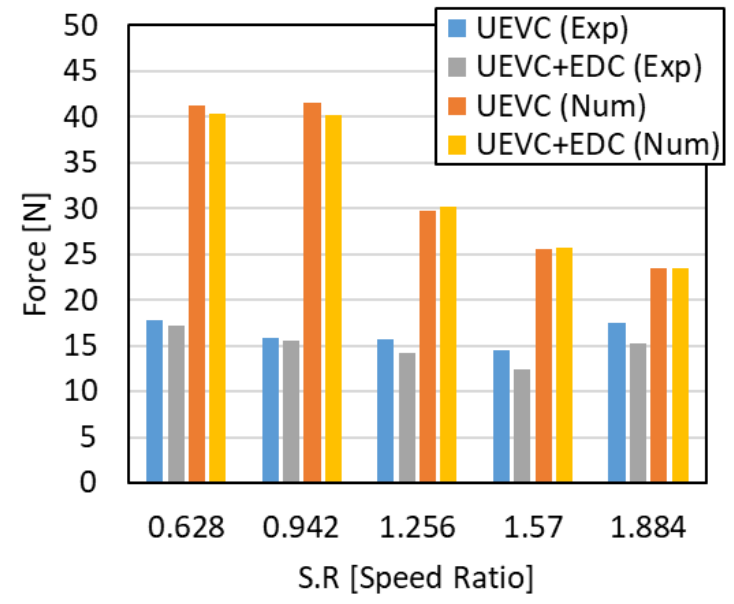

(a)

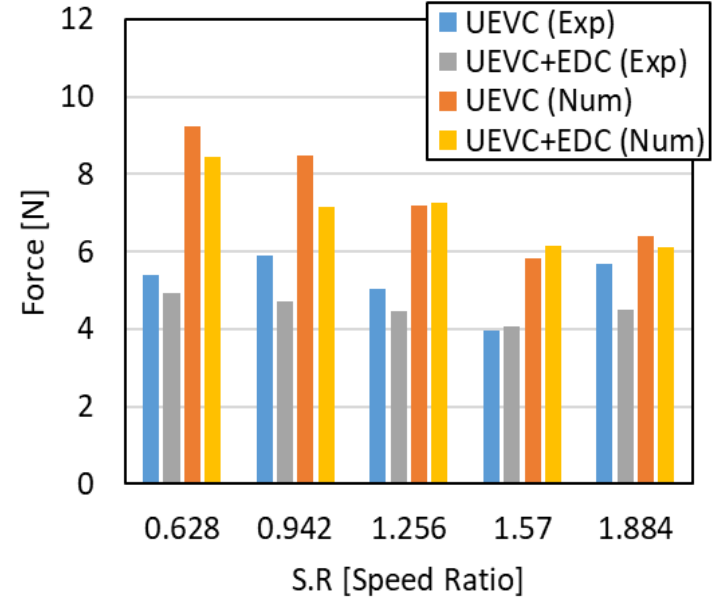

(b)

Fig. 16 Comparison of the cutting force of the experimental forces and numerical forces for UEVC and UEVC+EDC. (a) $F_{c}$, Principal Force (b) $F_{t}$, Thrust Force

Fig. 16 shows the validation between the numerical and experimental cutting forces of both UEVC and UEVC+EDC methods. The principal force $F_{c}$ was considered along the tangential direction of cutting in turning, and the thrust force $F_{t}$ was considered along the feed direction in turning. According to numerical results, adding the EDC method to the UEVC could decrease the cutting forces slightly in the low S.R. On the other hand, there was no significant effect at a higher S.R, especially for $F_{c}$ in the numerical study. The experimental results showed that a force reduction can still be observed at higher S.R. In this validation result, there was disagreement between the numerical and experimental results for both $F_{c}$ and $F_{t}$. Fig. 16 shows that the numerical value was higher than the experimental value. In the case of $F_{c}$, in numerical results, the cutting force ranged from 40 to $25 \mathrm{~N}$. By contrast, the cutting force $F_{c}$ in the experimental results was less than 20 $\mathrm{N}$. The nominal cutting speed in experimental validation was lower than in the numerical for a similar S.R. The nominal cutting speed was influenced directly by the validation results. The decreasing pattern was similar when the S.R was increased. When S.R $=1.884$, $F_{c}$ in the experimental case increased due to the very low cutting speed, possibly because higher friction occurs at the lowest cutting speed. A similar pattern with principal force in the thrust force was noted for the numerical result when S.R increased; a decreasing thrust force was observed with a low S.R. 
Numerical Analysis in Ultrasonic Elliptical Vibration Assisted Cutting (UEVC) Combined with Electrical Discharge Cutting (EDC) for Ti6Al4V

\subsection{Numerical Tool Temperature and Comparison}

Fig. 17 compares the numerical and experimental tool temperatures for the NC, UEVC, and UEVC+EDC method. Fig. 17 presents at low-speed ratio when S.R $=0.628$. Fig. 17(a) shows the node temperature of pattern 79, which is located on the rake face of the cutting tool. The node temperature in both UEVC and UEVC+EDC has a fluctuated graph compared to that in the NC. In NC, the numerical tool temperature constantly increased and reached a steady state with a mean value of $160.59{ }^{\circ} \mathrm{C}$. The numerical tool temperature in the UEVC fluctuates or even increases compared to NC. Similar evidence suggests that the tool temperature in UEVC is higher than NC during micro-grooving [74]. The average tool temperature in UEVC was higher than NC. Furthermore, in the case of UEVC+EDC, the effect of the Gaussian plasma spark induced heat into the rake face. The average tool temperature was $471.32{ }^{\circ} \mathrm{C}$. Hence, the material removal process in UEVC+EDC could be more effective than others because of the higher temperatures.

Fig. 17 (b) compares the numerical results with the experimental tool temperature measured using a type- $K$ thermocouple. The type- $K$ thermocouple was located under the cutting tool. The tool temperature was $60-80{ }^{\circ} \mathrm{C}$ because it was not located close to the rake face. Despite the different values from the numerical results, Fig. 17 (b) provides similar evidence that the average temperature in UEVC+EDC was the highest. Generally, the tool temperature increases from ambient temperature $25-30{ }^{\circ} \mathrm{C}$ to increase to a steady-state. The experimental temperature result for UEVC and UEVC+EDC must be examined using a median filter because of electrical signal disturbances from the ultrasonic generator and RC EDM generator. Fig. 17(c) presents the experimental tool temperature at near shear deformation. The IR camera results provided similar evidence that the tool temperature in the UEVC+EDC was highest at approximately $215^{\circ} \mathrm{C}$.

Fig. 18 shows the results for the case of a higher S.R ( $S . R=1.884)$. At a high S.R, a similar pattern can also be found. In the case of numerical tool temperature, compared to the low S.R, the tool temperature decreased for both UEVC and UEVC+EDC methods. The periodical cutting engagement with the workpiece decreased due to the more fluctuated pattern of the tool temperature. The tool vibrates more frequently at high S.R. As shown in Fig. 18 (b), the experimental tool temperature also showed similar evidence, with UEVC+EDC being the highest. On the other hand, the average value tool temperature in the UEVC+EDC was similar within the UEVC of an approximate $1{ }^{\circ} \mathrm{C}$ or $2^{\circ} \mathrm{C}$ difference. The UEVC+EDC graph pattern shows where there is a significant increase in the peak intensity. This might be due to the high plasma discharge with a sudden effective discharge gap. The IR camera results provided similar evidence that the tool temperature in UEVC+EDC was the highest, even with a high S.R, suggesting a better material removal process using the UEVC+EDC method. 
Numerical Analysis in Ultrasonic Elliptical Vibration Assisted Cutting (UEVC) Combined with Electrical Discharge Cutting (EDC) for Ti6Al4V

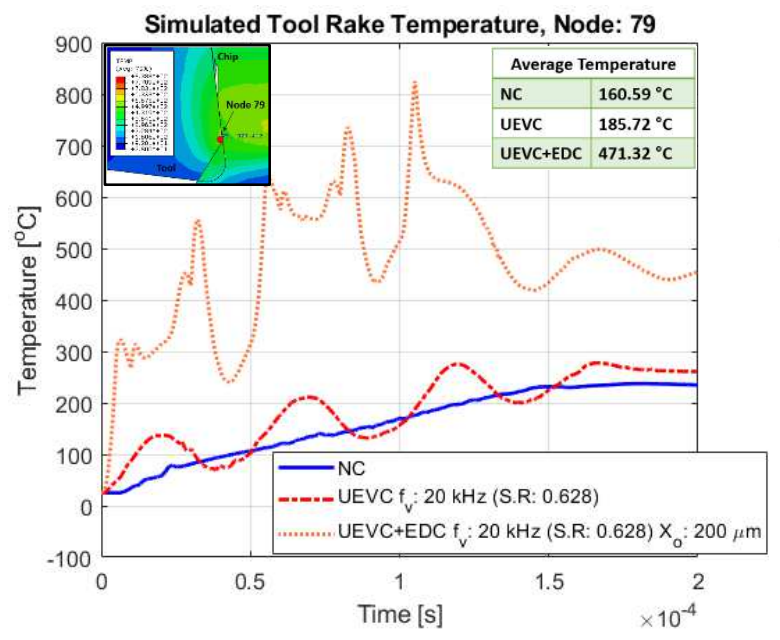

(a)

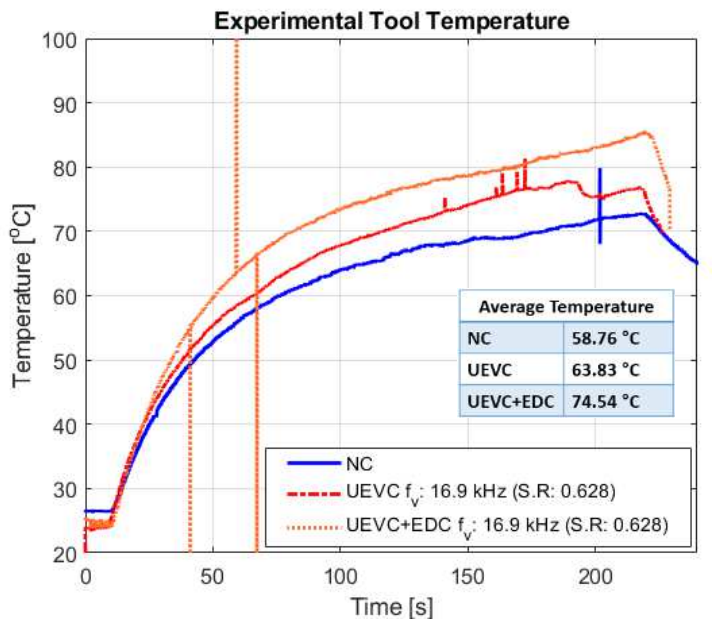

(b)
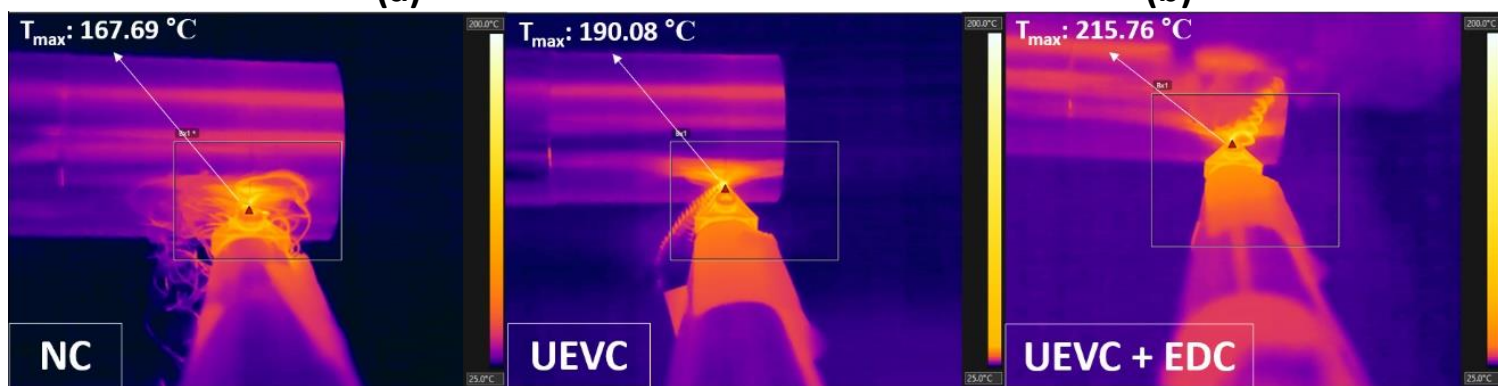

(c)

Fig. 17 Simulated tool temperature validation with the experimental results at S.R: 0.628 for NC, UEVC, and UEVC+EDC. (a) Simulated result, (b) Thermocouple measurement, and (c) IR camera measurement

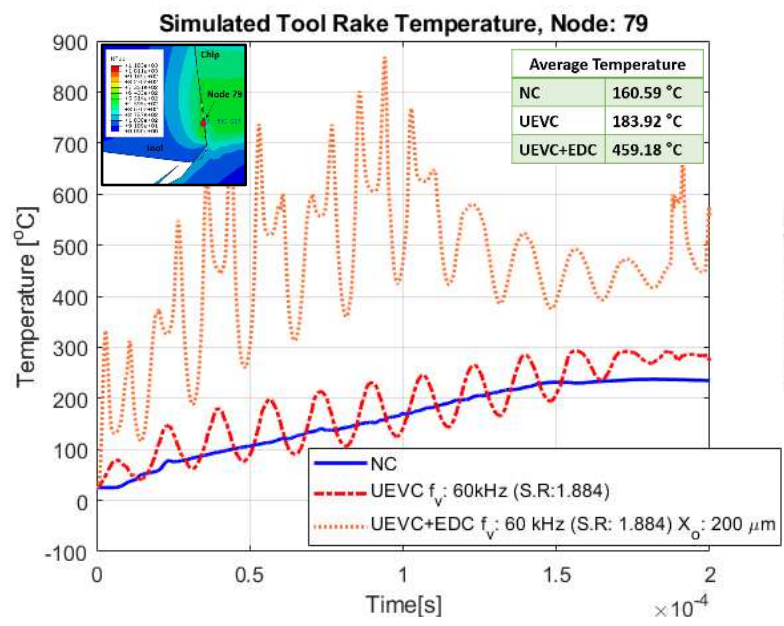

(a)

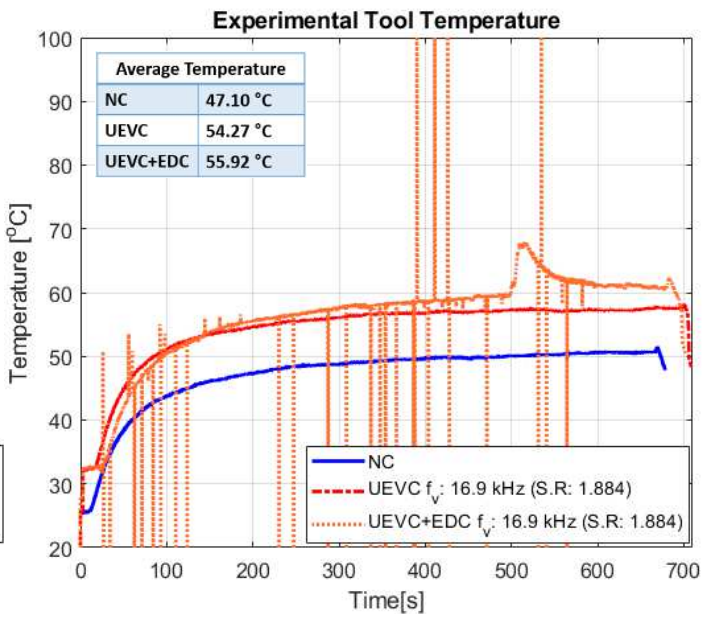

(b) 
Numerical Analysis in Ultrasonic Elliptical Vibration Assisted Cutting (UEVC) Combined with Electrical Discharge Cutting (EDC) for Ti6Al4V

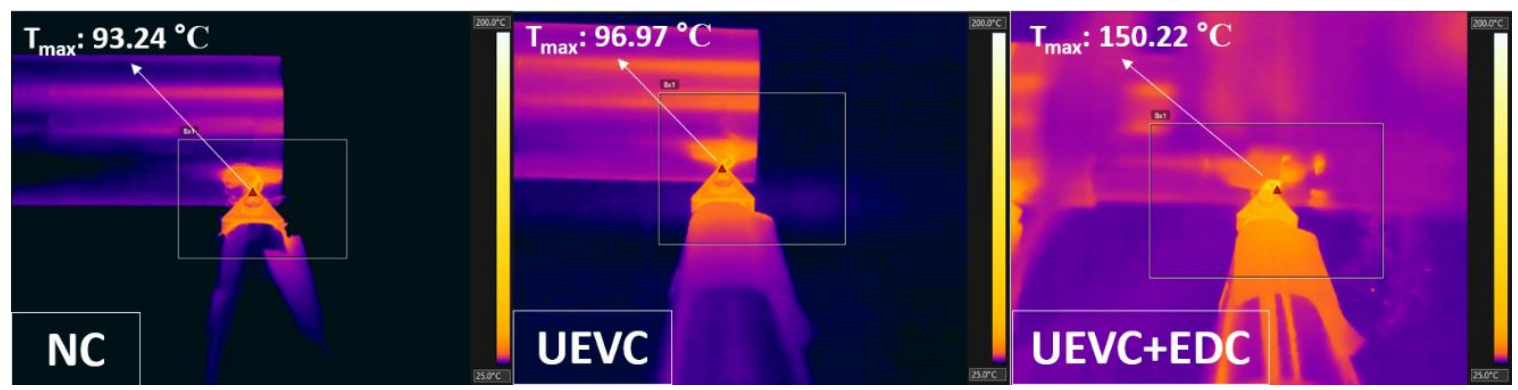

(c)

Fig. 18 Simulated tool temperature validation with experimental results at S.R: 1.884 for NC, UEVC, and UEVC+EDC. (a) Simulated result, (b) Thermocouple measurement, and (c) IR camera measurement

\section{CONCLUSION}

Numerical and experimental studies were performed on UEVC+EDC compared with the NC and UEVC methods in terms of the von Mises stress, cutting forces, and temperature. The following conclusions were drawn:

1. According to numerical results, the stress concentration on the shear zone in the UEVC+EDC decreased because of the vibrational tool effect (engage and disengage sequences) and Gaussian heat flux during the cutting process. The heat from the pulsed Gaussian heat flux induced the main shear zone, resulting in a decrease in von Mises stress.

2. According to the numerical results, the cutting forces in the UEVC+EDC decreased with increasing distance, Gaussian heat flux, and discharge voltage, but the cutting forces were not decreased by the high radius of Gaussian heat flux with a constant discharge voltage and current. In addition, the numerical results were verified by the experimental results. Although there were significant differences due to the different cutting speeds used, a similar trend was found in which the UEVC+EDC decreased the cutting forces.

3. The cutting forces decreased with increasing S.R in the numerical results. On the other hand, the cutting forces were high when the S.R was high experimentally because of the very low cutting speed and high friction.

4. According to the numerical and experimental results, the tool temperature in UEVC+EDC was highest. The discharge plasma spark increases the shear deformation zone and the tool temperature. These results suggest that a higher material removal state can be achieved using UEVC+EDC. 
Numerical Analysis in Ultrasonic Elliptical Vibration Assisted Cutting (UEVC) Combined with Electrical Discharge Cutting (EDC) for Ti6Al4V

\section{AUTHOR CONTRIBUTION}

Rendi Kurniawan: Writing-Original Draft, Conceptualization, Methodology, Formal

Analysis, and Software

Gun Chul Park, Ye In Kwak: Project Administration, Resources

Moran Xi, Jielin Chen: Visualization, Investigation

Saood Ali, Farooq Ahmed: Data Curation

Thirumalai S Kumaran: Validation

Chang Ping Li: Validation

Tae Jo Ko: Writing - Review \& Editing, Supervision, Funding Acquisition

\section{FUNDING}

The Basic Science Research Program supported this research through the National Research Foundation of Korea (NRF), funded by the Ministry of Science, ICT, and Future Planning (grant number NRF-2020R1A2B5B02001755).

\section{CODE AVAILABILITY}

The code is available as requested to the authors.

\section{AVAILABITY OF DATA AND MATERIAL}

The availability of data and material are available as requested to the authors.

\section{DECLARATIONS}

ETHICS APPROVAL

Not applicable

\section{CONSENT TO PARTICIPATE}

Not applicable

\section{CONSENT FOR PUBLICATION}

Not applicable

\section{CONFLICT OF INTEREST}

The authors declare no competing interests. The authorship and funding have been declared properly. 
Numerical Analysis in Ultrasonic Elliptical Vibration Assisted Cutting (UEVC) Combined with Electrical Discharge Cutting (EDC) for Ti6Al4V

\section{REFERENCES}

1. Kurniawan R, Kumaran ST, Ali S, et al. (2018) Experimental and analytical study of ultrasonic elliptical vibration cutting on AISI 1045 for sustainable machining of round-shaped microgroove pattern. Int J Adv Manuf Technol 98:2031-2055. https://doi.org/10.1007/s00170-018-2359-1

2. Tan R, Zhao X, Guo S, et al. (2020) Sustainable production of dry-ultra-precision machining of Ti-6Al-4V alloy using PCD tool under ultrasonic elliptical vibrationassisted cutting. J Clean Prod 248:119254. https://doi.org/10.1016/j.jclepro.2019.119254

3. Haidong Z, Shuguang L, Ping Z, Di K (2017) Process modeling study of the ultrasonic elliptical vibration cutting of Inconel 718. Int J Adv Manuf Technol 92:2055-2068. https://doi.org/10.1007/s00170-017-0266-5

4. Huang W, Yu D, Zhang X, et al. (2018) Ductile-regime machining model for ultrasonic elliptical vibration cutting of brittle materials. J Manuf Process 36:6876. https://doi.org/10.1016/j.jmapro.2018.09.029

5. Zhu W Le, He Y, Ehmann KF, et al. (2016) Theoretical and Experimental Investigation on Inclined Ultrasonic Elliptical Vibration Cutting of Alumina Ceramics. J Manuf Sci Eng Trans ASME 138:. https://doi.org/10.1115/1.4033605

6. Lotfi M, Amini S (2018) FE simulation of linear and elliptical ultrasonic vibrations in turning of Inconel 718. Proc Inst Mech Eng Part E J Process Mech Eng 232:438448. https://doi.org/10.1177/0954408917715533

7. Ma C, Shamoto E, Moriwaki T, et al. (2005) Suppression of burrs in turning with ultrasonic elliptical vibration cutting. Int J Mach Tools Manuf 45:1295-1300. https://doi.org/10.1016/j.ijmachtools.2005.01.011

8. Nath C, Rahman M, Neo KS (2009) Machinability study of tungsten carbide using PCD tools under ultrasonic elliptical vibration cutting. Int J Mach Tools Manuf 49:1089-1095. https://doi.org/10.1016/j.ijmachtools.2009.07.006

9. Kurniawan R, Kiswanto G, Ko TJ (2017) Surface roughness of two-frequency elliptical vibration texturing (TFEVT) method for micro-dimple pattern process. Int J Mach Tools Manuf 116:77-95. https://doi.org/10.1016/j.ijmachtools.2016.12.011

10. Yang Z, Zhu L, Zhang G, et al. (2020) Review of ultrasonic vibration-assisted machining in advanced materials. Int J Mach Tools Manuf 156:103594. https://doi.org/10.1016/j.ijmachtools.2020.103594

11. Kurniawan R, Ko TJ, Ping LC, et al. (2017) Development of a two-frequency, elliptical-vibration texturing device for surface texturing. J Mech Sci Technol 31:3465-3473. https://doi.org/10.1007/s12206-017-0635-x

12. Brehl D, Dow T (2008) Review of vibration-assisted machining. Precis Eng 32:153172. https://doi.org/10.1016/j.precisioneng.2007.08.003

13. Kiswanto G, Libyawati W (2019) Fundamental Aspects in Designing Vibration Assisted Machining: A Review. IOP Conf Ser Mater Sci Eng 494:. https://doi.org/10.1088/1757-899X/494/1/012095 
Numerical Analysis in Ultrasonic Elliptical Vibration Assisted Cutting (UEVC) Combined with Electrical Discharge Cutting (EDC) for Ti6Al4V

14. Zheng L, Chen W, Huo D (2020) Review of vibration devices for vibration-assisted machining. Int J Adv Manuf Technol 108:1631-1651.

https://doi.org/10.1007/s00170-020-05483-8

15. Chen W, Huo D, Shi Y, Hale JM (2018) State-of-the-art review on vibrationassisted milling: principle, system design, and application. Int J Adv Manuf Technol 97:2033-2049. https://doi.org/10.1007/s00170-018-2073-z

16. Hafiz MSA, Kawaz MHA, Mohamad WNF, et al. (2017) A review on feasibility study of ultrasonic assisted machining on aircraft component manufacturing. IOP Conf Ser Mater Sci Eng 270:. https://doi.org/10.1088/1757-899X/270/1/012034

17. Xu S, Kuriyagawa T, Shimada K, Mizutani M (2017) Recent advances in ultrasonicassisted machining for the fabrication of micro/nano-textured surfaces. Front Mech Eng 12:33-45. https://doi.org/10.1007/s11465-017-0422-5

18. Kang D, Zou P, Wu H, et al. (2019) Study on ultrasonic vibration-assisted cutting of Nomex honeycomb cores. Int J Adv Manuf Technol 104:979-992. https://doi.org/10.1007/s00170-019-03883-z

19. Chen W, Zheng L, Teng X, et al. (2019) Finite element simulation and experimental investigation on cutting mechanism in vibration-assisted micromilling. Int J Adv Manuf Technol 105:4539-4549.

https://doi.org/10.1007/s00170-019-03402-0

20. Jamshidi $\mathrm{H}$, Nategh MJ (2013) Theoretical and experimental investigation of the frictional behavior of the tool-chip interface in ultrasonic-vibration assisted turning. Int J Mach Tools Manuf 65:1-7. https://doi.org/10.1016/j.ijmachtools.2012.09.004

21. Liu X, Wu D, Zhang J, et al. (2019) Analysis of surface texturing in radial ultrasonic vibration-assisted turning. J Mater Process Technol 267:186-195. https://doi.org/10.1016/j.jmatprotec.2018.12.021

22. Liu X, Wu D, Zhang J (2018) Fabrication of micro-textured surface using feeddirection ultrasonic vibration-assisted turning. Int J Adv Manuf Technol 97:38493857. https://doi.org/10.1007/s00170-018-2082-y

23. Liu X, Zhang J, Hu X, Wu D (2019) Influence of tool material and geometry on micro-textured surface in radial ultrasonic vibration-assisted turning. Int J Mech Sci 152:545-557. https://doi.org/10.1016/j.ijmecsci.2019.01.027

24. Li G, Wang B, Xue J, et al. (2019) Development of vibration-assisted micro-milling device and effect of vibration parameters on surface quality and exit-burr. Proc Inst Mech Eng Part B J Eng Manuf 233:1723-1729. https://doi.org/10.1177/0954405418774592

25. FI LC, Gonz A (2020) Estimation of Specific Cutting Energy in an S235 Alloy for Multi-Directional Ultrasonic Vibration-Assisted Machining Using the Finite Element Method. Materials (Basel) 13(3):

26. He Y, Zou P, Zhu W Le, Ehmann KF (2017) Ultrasonic elliptical vibration cutting of hard materials: simulation and experimental study. Int J Adv Manuf Technol 91:363-374. https://doi.org/10.1007/s00170-016-9716-8 
Numerical Analysis in Ultrasonic Elliptical Vibration Assisted Cutting (UEVC) Combined with Electrical Discharge Cutting (EDC) for Ti6Al4V

27. Kong C, Wang D (2018) Numerical investigation of the performance of elliptical vibration cutting in machining of AISI 1045 steel. Int J Adv Manuf Technol 98:715727. https://doi.org/10.1007/s00170-018-2277-2

28. Kurniawan R, Kiswanto G, Ko TJ (2016) Micro-dimple pattern process and orthogonal cutting force analysis of elliptical vibration texturing. Int J Mach Tools Manuf 106:127-140. https://doi.org/10.1016/j.ijmachtools.2016.03.007

29. Jieqiong $L$, Jinguo $H$, Xiaoqin $Z$, et al. (2016) Study on predictive model of cutting force and geometry parameters for oblique elliptical vibration cutting. Int J Mech Sci 117:43-52. https://doi.org/10.1016/j.ijmecsci.2016.08.004

30. Shu L, Sugita N (2020) Analysis of fracture, force, and temperature in orthogonal elliptical vibration-assisted bone cutting. J Mech Behav Biomed Mater 103:103599. https://doi.org/10.1016/j.jmbbm.2019.103599

31. Zhao L, Zhang J, Zhang J, Hartmaier A (2021) Atomistic investigation of machinability of monocrystalline $3 \mathrm{C}-\mathrm{SiC}$ in elliptical vibration-assisted diamond cutting. Ceram Int 47:2358-2366. https://doi.org/10.1016/j.ceramint.2020.09.078

32. Dai H, Du H, Chen J, Chen G (2019) Influence of elliptical vibration on the behavior of silicon during nanocutting. Int J Adv Manuf Technol 102:3597-3612. https://doi.org/10.1007/s00170-019-03361-6

33. Zhang J, Zhang J, Cui T, et al. (2017) Sculpturing of single crystal silicon microstructures by elliptical vibration cutting. J Manuf Process 29:389-398. https://doi.org/10.1016/j.jmapro.2017.09.003

34. Zhang J, Han L, Zhang J, et al. (2019) Brittle-to-ductile transition in elliptical vibration-assisted diamond cutting of reaction-bonded silicon carbide. J Manuf Process 45:670-681. https://doi.org/10.1016/j.jmapro.2019.08.005

35. Yang Y, Pan Y, Guo P (2017) Structural coloration of metallic surfaces with micro/nano-structures induced by elliptical vibration texturing. Appl Surf Sci 402:400-409. https://doi.org/10.1016/j.apsusc.2017.01.026

36. Zhang J, Zhang J, Rosenkranz A, et al. (2019) Frictional properties of surface textures fabricated on hardened steel by elliptical vibration diamond cutting. Precis Eng 59:66-72. https://doi.org/10.1016/j.precisioneng.2019.06.001

37. Shamoto E, Suzuki N, Hino R (2008) Analysis of 3D elliptical vibration cutting with thin shear plane model. CIRP Ann - Manuf Technol 57:57-60.

https://doi.org/10.1016/j.cirp.2008.03.073

38. Kurniawan R, Ali S, Park KM, et al. (2019) Development of a Three-Dimensional Ultrasonic Elliptical Vibration Transducer (3D-UEVT) Based on Sandwiched Piezoelectric Actuator for Micro-grooving. Int J Precis Eng Manuf. https://doi.org/10.1007/s12541-019-00126-9

39. Kurniawan R, Ko TJ, Kumaran ST, Ahmed F (2021) 3-DOF ultrasonic elliptical vibration tool holder based on coupled resonance modes for manufacturing micro-groove. Precis Eng 67:. https://doi.org/10.1016/j.precisioneng.2020.10.002

40. Kurniawan R, Ko TJ (2019) Surface topography analysis in three-dimensional elliptical vibration texturing ( 3D-EVT ). Int J Adv Manuf Technol 1-21 
Numerical Analysis in Ultrasonic Elliptical Vibration Assisted Cutting (UEVC) Combined with Electrical Discharge Cutting (EDC) for Ti6Al4V

41. Wang $\mathrm{H}, \mathrm{Hu} \mathrm{Y}$, Cong $\mathrm{W}$, et al. (2020) A novel investigation on horizontal and 3D elliptical ultrasonic vibrations in rotary ultrasonic surface machining of carbon fiber reinforced plastic composites. J Manuf Process 52:12-25. https://doi.org/10.1016/j.jmapro.2020.01.027

42. Lotfi M, Amini S, Akbari J (2020) Surface integrity and microstructure changes in 3D elliptical ultrasonic assisted turning of Ti-6Al-4V: FEM and experimental examination. Tribol Int 106492. https://doi.org/10.1016/j.triboint.2020.106492

43. Kurniawan R, Ali S, Ko TJ (2020) Measurement of wettability on rhombohedral pattern fabricated by using 3D-UEVT. Meas J Int Meas Confed 160:107784. https://doi.org/10.1016/j.measurement.2020.107784

44. Ali S, Kurniawan R, Ko TJ (2021) Development of 3D Resonant Elliptical Vibration Transducer for Dual-Frequency Micro-Dimple Surface Texturing. Int J Precis Eng Manuf. https://doi.org/10.1007/s12541-021-00551-9

45. Jeon Y, Park HW, Lee CM (2013) Current research trends in external energy assisted machining. Int J Precis Eng Manuf 14:337-342.

https://doi.org/10.1007/s12541-013-0047-5

46. Lei S, Pfefferkorn F (2007) A review of thermally assisted machining. Proc ASME Int Manuf Sci Eng Conf 2007, MSEC2007 325-336.

https://doi.org/10.1115/MSEC2007-31096

47. Venkatesan K, Ramanujam R, Kuppan P (2014) Laser assisted machining of difficult to cut materials: Research opportunities and future directions - $A$ comprehensive review. Procedia Eng 97:1626-1636.

https://doi.org/10.1016/j.proeng.2014.12.313

48. Jeon Y, Lee CM (2012) Current research trend on laser assisted machining. Int J Precis Eng Manuf 13:311-317. https://doi.org/10.1007/s12541-012-0040-4

49. Tian $Y$, Shin YC (2006) Thermal modeling for laser-assisted machining of silicon nitride ceramics with complex features. J Manuf Sci Eng Trans ASME 128:425434. https://doi.org/10.1115/1.2162906

50. Leshock CE, Kim JN, Shin YC (2001) Plasma enhanced machining of Inconel 718: Modeling of workpiece temperature with plasma heating and experimental results. Int J Mach Tools Manuf 41:877-897. https://doi.org/10.1016/S08906955(00)00106-1

51. Shams OA, Pramanik A, Chandratilleke TT (2017) Thermal-Assisted Machining of Titanium Alloys. In: Advanced Manufacturing Technologies. pp 49-76

52. Jung ST, Kurniawan R, Kumaran ST, et al. (2020) Mechanism study of microelectrical discharge drilling method during micro-dimpling. J Mech Sci Technol 34:2549-2559. https://doi.org/10.1007/s12206-020-0530-8

53. Kurniawan R, Thirumalai Kumaran S, Arumuga Prabu V, et al. (2017) Measurement of burr removal rate and analysis of machining parameters in ultrasonic assisted dry EDM (US-EDM) for deburring drilled holes in CFRP composite. Measurement 110:98-115. https://doi.org/10.1016/j.measurement.2017.06.008 
Numerical Analysis in Ultrasonic Elliptical Vibration Assisted Cutting (UEVC) Combined with Electrical Discharge Cutting (EDC) for Ti6Al4V

54. Leão FN, Pashby IR (2004) A review on the use of environmentally-friendly dielectric fluids in electrical discharge machining. J Mater Process Technol 149:341-346. https://doi.org/10.1016/j.jmatprotec.2003.10.043

55. Shen Y, Liu Y, Zhang Y, et al. (2015) High-speed dry electrical discharge machining. Int J Mach Tools Manuf 93:19-25. https://doi.org/10.1016/j.ijmachtools.2015.03.004

56. Mohd Abbas N, Solomon DG, Fuad Bahari M (2007) A review on current research trends in electrical discharge machining (EDM). Int J Mach Tools Manuf 47:12141228. https://doi.org/10.1016/j.ijmachtools.2006.08.026

57. Kumar S, Singh R, Singh TP, Sethi BL (2009) Surface modification by electrical discharge machining: A review. J Mater Process Technol 209:3675-3687. https://doi.org/10.1016/j.jmatprotec.2008.09.032

58. Shrivastava PK, Dubey AK (2014) Electrical discharge machining-based hybrid machining processes: A review. Proc Inst Mech Eng Part B J Eng Manuf 228:799825. https://doi.org/10.1177/0954405413508939

59. Chakraborty S, Dey V, Ghosh SK (2015) A review on the use of dielectric fluids and their effects in electrical discharge machining characteristics. Precis Eng 40:1-6. https://doi.org/10.1016/j.precisioneng.2014.11.003

60. Prakash V, Kumar P, Singh PK, et al. (2019) Micro-electrical discharge machining of difficult-to-machine materials: A review. Proc Inst Mech Eng Part B J Eng Manuf 233:339-370. https://doi.org/10.1177/0954405417718591

61. Kandpal BC, kumar J, Singh H (2015) Machining of Aluminium Metal Matrix Composites with Electrical Discharge Machining - A Review. Mater Today Proc 2:1665-1671. https://doi.org/10.1016/j.matpr.2015.07.094

62. Gangil M, Pradhan MK, Purohit R (2017) Review on modelling and optimization of electrical discharge machining process using modern Techniques. Mater Today Proc 4:2048-2057. https://doi.org/10.1016/j.matpr.2017.02.050

63. Macedo FTB, Wiessner M, Hollenstein C, et al. (2019) Anode Power Deposition in Dry EDM. Int J Precis Eng Manuf - Green Technol 6:197-210. https://doi.org/10.1007/s40684-019-00051-2

64. Dhakar K, Chaudhary K, Dvivedi A, Bembalge O (2019) An environment-friendly and sustainable machining method: near-dry EDM. Mater Manuf Process 34:1307-1315. https://doi.org/10.1080/10426914.2019.1643471

65. Shervani-Tabar MT, Maghsoudi K, Shabgard MR (2013) Effects of simultaneous ultrasonic vibration of the tool and the workpiece in ultrasonic assisted EDM. Int J Comput Methods Eng Sci Mech 14:1-9. https://doi.org/10.1080/15502287.2012.698696

66. Han W, Kunieda M (2019) A novel method to switch machining mode between Micro-ECM and Micro-EDM using oxide film on surface of tungsten electrode. Precis Eng 56:455-465. https://doi.org/10.1016/j.precisioneng.2019.02.002

67. Li CP, Kim MY, Islam MM, Ko TJ (2016) Mechanism analysis of hybrid machining process comprising EDM and end milling. J Mater Process Technol 237:309-319. https://doi.org/10.1016/j.jmatprotec.2016.06.022 
Numerical Analysis in Ultrasonic Elliptical Vibration Assisted Cutting (UEVC) Combined with Electrical Discharge Cutting (EDC) for Ti6Al4V

68. Baghel R, Mali HS, Biswas SK (2019) Parametric optimization and surface analysis of diamond grinding-assisted EDM of TiN-Al2O3 ceramic composite. Int J Adv Manuf Technol 100:1183-1192. https://doi.org/10.1007/s00170-018-1842-z

69. Zhang C, Zou R, Yu Z, Natsu W (2020) Micro EDM aided by ultrasonic vibration in nitrogen plasma jet and mist. Int J Adv Manuf Technol 106:5269-5276. https://doi.org/10.1007/s00170-020-05032-3

70. Li C, Xu M, Yu Z, et al. (2020) Electrical discharge-assisted milling for machining titanium alloy. J Mater Process Technol 285:116785. https://doi.org/10.1016/j.jmatprotec.2020.116785

71. Ying Z, Shu L, Sugita N (2020) Experimental and Finite Element Analysis of Force and Temperature in Ultrasonic Vibration Assisted Bone Cutting. Ann Biomed Eng 48:1281-1290. https://doi.org/10.1007/s10439-020-02452-w

72. Xiang D, Shi Z, Feng H, et al. (2019) Finite element analysis of ultrasonic assisted milling of SiCp/Al composites. Int J Adv Manuf Technol 105:3477-3488. https://doi.org/10.1007/s00170-019-04542-z

73. Lotfi M, Amini S (2017) Experimental and numerical study of ultrasonicallyassisted drilling. Ultrasonics 75:185-193. https://doi.org/10.1016/j.ultras.2016.11.009

74. Kurniawan R, Kumaran ST, Ko TJ (2021) Finite Element Analysis in Ultrasonic Elliptical Vibration Cutting (UEVC) During Micro-Grooving in AISI 1045. Int J Precis Eng Manuf. https://doi.org/10.1007/s12541-021-00554-6

75. Chen G, Ren C, Yang X, et al. (2011) Finite element simulation of high-speed machining of titanium alloy (Ti-6Al-4V) based on ductile failure model. Int J Adv Manuf Technol 56:1027-1038. https://doi.org/10.1007/s00170-011-3233-6

76. Zhang YC, Mabrouki T, Nelias D, Gong YD (2011) Chip formation in orthogonal cutting considering interface limiting shear stress and damage evolution based on fracture energy approach. Finite Elem Anal Des 47:850-863. https://doi.org/10.1016/j.finel.2011.02.016

77. Kurnia W, Tan PC, Tan PC, et al. (2007) Electro-thermal modelling of anode and cathode in micro-EDM. https://doi.org/10.1088/0022-3727/40/8/015

78. Shao B, Rajurkar KP (2015) Modelling of the crater formation in micro-EDM. Procedia CIRP 33:376-381. https://doi.org/10.1016/j.procir.2015.06.085

79. Liu JF, Guo YB (2016) Thermal Modeling of EDM with Progression of Massive Random Electrical Discharges. Procedia Manuf 5:495-507. https://doi.org/10.1016/j.promfg.2016.08.041

80. Özel T, Zeren E (2004) Determination of work material flow stress and friction for FEA of machining using orthogonal cutting tests. J Mater Process Technol 153154:1019-1025. https://doi.org/10.1016/j.jmatprotec.2004.04.162

81. Ayed Y, Germain G, Salem W Ben, Hamdi H (2014) Experimental and numerical study of laser-assisted machining of Ti6Al4V titanium alloy. Finite Elem Anal Des 92:72-79. https://doi.org/10.1016/j.finel.2014.08.006

82. Kurniawan R, Ahmed F, Ali S, et al. (2021) Analytical, FEA, and experimental research of 2D-Vibration Assisted Cutting (2D-VAC) in titanium alloy Ti6Al4V. Int J Adv Manuf Technol. https://doi.org/10.1007/s00170-021-07831-8 